Article

\title{
Agriculture 4.0 and Smart Sensors. The Scientific Evolution of Digital Agriculture: Challenges and Opportunities
}

\author{
Michele Kremer Sott 1,* , Leandro da Silva Nascimento ${ }^{2}$, Cristian Rogério Foguesatto ${ }^{1}$, Leonardo \\ B. Furstenau ${ }^{2}$, Kadígia Faccin ${ }^{1}$, Paulo Antônio Zawislak ${ }^{2}$, Bruce Mellado ${ }^{3}$, Jude Dzevela Kong ${ }^{4}$ \\ and Nicola Luigi Bragazzi ${ }^{4, *}$ \\ ${ }^{1}$ Unisinos University; sott.mk@gmail.com (M.K.S.), cristian17agro@gmail.com (C.R.F.), kadigiaf@unisinos.br \\ (K.F.) \\ ${ }^{2}$ Federal University of Rio Grande do Sul; leonardo.furstenau@ufrgs.br (L.B.F.), lesnasc@gmail.com (L.S.N.), \\ pazawislak@ea.ufrgs.br (P.A.Z.) \\ ${ }^{3}$ School of Physics and Institute for Collider Particle Physics, University of the Witwatersrand, Johannes- 7 \\ burg, Wits 2050, South Africa; bruce.mellado@wits.ac.za \\ ${ }^{4}$ Department of Mathematics and Statistics, York University; jdkong@yorku.ca \\ *Correspondence: sott.mk@gmail.com (M.K.S.); robertobragazzi@gmail.com (N.L.B.)
}

\begin{abstract}
The agriculture sector is one of the backbones of many countries' economies and its processes have been changing in order to enable technological adoption to increase productivity, quality, and sustainable development. In this research, we present a theoretical reflection through a scientific mapping of the adoption of precision techniques and breakthrough technologies in agriculture, the so-called Precision Agriculture (PA) and Agriculture 4.0 (A4.0). To do this, we used 4,694 documents from the Web of Science database to perform a Bibliometric Performance and Network Analysis (BPNA) of the literature with the support of the PICOC protocol and the SciMAT software. Our findings present 22 strategic themes related to Digital Agriculture (DA) such as Internet of Things (IoT) and Climate-smart Agriculture (CSA) among others, and the thematic network structures of the motor themes and the thematic evolution structure of the field of the study over time. In addition, our results discuss the main challenges and opportunities of DA. Our findings have the potential to provide insights for practitioners and researchers in decision-making and pave the way for future works.
\end{abstract}

Keywords: precision agriculture; agriculture 4.0; digital agriculture; smart farming; industry 4.0; sustainability; innovation; bibliometrics; science mapping.

\section{Introduction}

Agriculture has been revolutionized over time, reaching the concepts of Precision Agriculture (PA) and Agriculture 4.0 (A4.0) that give face to Digital Agriculture (DA). Around 10,000 years ago, humans began to dedicate efforts to domesticating plants and animals, spreading seeds, planting seedlings, and using animal force to plow the land [1]. This revolution that changed human life and transformed hunter-gatherers into farmers is called the Neolithic Revolution or the First Agricultural Revolution [2]. Although this revolution was a great leap for mankind, as it allowed the cultivation of plants and guaranteed food for the population, the new activities demanded more hours of work, and this dedication to agriculture generated a surplus of food that allowed the population to multiply, and created elites who owned land and food [2]. Between the First Agricultural Revolution and the prosperous and abundant society that we have today, thousands of years have passed, several transformations in the way of production, and several difficulties related to economic niches, malnutrition and wars over fields and cultures [2]. These significant disadvantages have led to new transformations and revolutions in the field of agriculture [3].

In the 19th century, Agriculture 2.0, also called Second Agricultural Revolution, changed farming by adding machinery, selective breeding, animal fertilizer, crop rotation, reapers and tractors that 
shaped the first steps of modern agriculture [1]. In this frame, food started to be produced faster, but farmers were hindered by rust, pests, and soil depletion. New techniques and technologies have increased food surplus and reduced the need for labor in agriculture, forcing the migration of workers and the urbanization and the growth of cities [4,5]. This allocation of the workforce in cities was part of the industrial revolution, which stimulated the rise of manufacturing industries [4].

To deal with the challenges of the Second Agricultural Revolution, the Agriculture 3.0 or the Third Agricultural Revolution emerged in the 20th and early 21st centuries. In a frame of this period, between 1966 and 1985 the concept of Green Revolution emerged, especially in terms of the high use of technology such as biotechnology and genetic engineering to generate genetically varieties, hybrid plants and animals [6,7], and providing a breakthrough in agriculture. The third revolution was characterized by adding new technologies such as GNSS (Global Navigation Satellite System) to monitor animals and crops, computers and devices for data management and analysis of agricultural production information, robots, chemicals, fertilizers, and irrigation systems to increase productivity and production quality [1]. These transformations had a great impact on the quality of agricultural production and on the societal, economic, and environmental pillars of sustainability [8].

The concept of PA emerged in 1980 and represents the use of precision techniques and technologies used singly or in combination [9] to control the field variability [10,11]. Despite the concept of PA appeared in the Third Agricultural Revolution, its techniques and technologies are used in the context of the Fourth Agricultural Revolution. A4.0 emerged with the new technologies of the Fourth Industrial Revolution, also called Industry 4.0, in 2011 [11] and represents the use of technologies such as Internet of Things (IoT), Artificial Intelligence (AI), Big data (BD), Cloud Computing and other smart systems and devices for managing crops and farms [11,12]. In this sense, both terms are related to DA, which can be perceived as a driver for change and evolution in both sustainability and food security as well as efficiency and productivity. Economies of scope and scale may take on a new dimension with DA. Drones, IoT and BD, for instance, are to be as attached to individual firm strategic goals as to collective sustainable and inclusive agriculture objectives.

Even so, despite the revolutions have solved countless problems related to food production and security, the increase in population and the scarcity of resources are worrisome challenges for modern agriculture. Nowadays, almost one billion people go to sleep hungry every day [13]. The human population is expected to reach 9 billion by 2050 [11] increasing food demand by up to $50 \%$ [14]. Most of these people are expected to live in the regions of South Asia and sub-Saharan Africa, where more than $20 \%$ of the current population are food insecure [15]. In addition, agriculture is responsible for the consumption of $70 \%$ of the world's drinking water [11], human consumption has tripled in the last 50 years, and the exploitation of resources is $30 \%$ greater than nature's ability to regenerate [16]. In this perspective, the challenges of producing more food with less environmental impact are evident [17]. Given this backdrop, emerging technologies can be enablers for sustainable agricultural production, and the main challenges and opportunities of technological adoption need to be explored.

Several studies have revised the field of agriculture to understand the effects of technology adoption and its potential to deal with challenges related to food production for the current and future generations. Kim et al. (2019) and Raparelli and Bajocco (2019) [18,19] presented bibliometric analyzes on the use of Unmanned Aerial Vehicles (UAV) in agriculture, and Terence and Purushothaman (2020) and Navarro et al. (2020) [20,21] systematically reviewed the use of IoT in smart farms. In addition, previous studies explored the use of Machine Learning (ML) techniques [22-24], geospatial technology [25], and BD for smart farming [26,27]. Extensive reviews show the state of the art of PA technologies [28] and the main factors that influence technological adoption [29]. Although some reviews have already been carried out, no study has presented the complete evolution of the field of study over time or discussed the process of digitalization of agriculture. The present paper addresses precisely this literature gap, by highlighting the main challenges and opportunities related to DA.

Due to the transformational potential of emerging technologies for agriculture presented in the aforementioned reviews, the present paper is devoted to presenting a scientific mapping to identify strategic themes, the thematic evolution structure and the main challenges and opportunities of DA. For this, the PICOC protocol (Population, Intervention, Comparison, Outcome, and Context) was 
used to guide and ensure the quality of this study, and the SciMAT (Science Mapping Analysis Software Tool) software developed by Cobo et al. (2012) [30] was used for data treatment and generation of the strategic diagram and the evolutionary map of the field of study.

The paper is organized as follows: Section 2 presents the research background. Section 3 contains materials and methods. Results and discussions are presented in Section 4 . The main challenges and opportunities are presented in Section 5, and Section 6 presents the conclusions, limitations, and suggestions for further research.

\section{Research background}

Different terms and many contradictions exist related to PA and A4.0 [31]. Although some authors associate them, in this work we present a distinction between PA and A4.0. While PA is often associated with issues of field variability and specific analyzes and technologies, such as application of agricultural inputs in areas with the greatest productive potential (e.g., the use of georeferenced data for the application of chemicals according to the needs of each area), A4.0 goes beyond the analysis of field variability and aims to manage farms with awareness of context and situation, and to create a value chain that integrates stakeholders, technologies and agricultural processes $[11,31,32]$. Due to the variety of concepts and interpretations related to technological adoption in agriculture, in this research the term Digital Agriculture is used to describe both concepts associated with digital transformation in agriculture without considering the technological level.

\subsection{Precision Agriculture}

The PA concept represents the use of techniques and emerging technologies for crop management, pest control and field improvement [11,33], with PA was possible to increase crop quality and crop productivity. Since 1980, with the appearance of the concept, there has been a considerable increase in the use of technology in agriculture. For instance, the global soybean production could be 32 million tons higher if the PA were massively adopted [34]. Progressively, new techniques and technologies were related to the term, which was gradually being explored by researchers and practitioners to provide a range of advantages for the primary sector [11].

In addition, to increase crop productivity and farm profitability, PA is a key factor for reducing environmental impact. This occurs due to the more cost-effect use of agricultural productive inputs (e.g., chemical and fuel). Therefore, several studies have been showing the importance of the adoption of PA for reducing environmental impacts [35-37], for instance, the efficient use of phosphorus (P) and potassium (K) through PA technologies contributes to agriculture more sustainable [34]. PA research is also related to the identification of management zones [38,39], analysis and management of soil and plant nutrients [40-42], UAV applications for capture and analysis of plantation data [43,44], farmers' perception [45] and others.

\subsection{Agriculture 4.0}

The concept of A4.0 emerged after the development of Industry 4.0 in 2011, and seeks to make use of the same technologies used by factories of the future to create a new level of agricultural production for the sake of food safety and protection of the environment [11]. A4.0 represents the use of emerging technologies to create a value chain to integrate organizations, farmers, customers, and all stakeholders in favor of economic, social, and environmental sustainability. Therefore, A4.0 is important for mitigating several global concerns related to productivity, profitability, cost reduction and efficiency [11], and including mitigating climate changes effects and allocating agricultural resources reasonably [35]. Given this, there is an evident growing interest in the subject of digital agriculture [46].

Unlike the PA, A4.0 is broader and more comprehensive, as it seeks to integrate all actors in agrifood production through a technological value chain. In this perspective, A4.0 goes beyond local and specific analyzes to include all agricultural processes. Studies related to A4.0 address the development of decision support systems to integrate all members of the production chain [1], responsible innovation [47], real-time integration of IoT for agriculture [48], and the potential of A4.0 to address issues associated with environmental sustainability (e.g., carbon emissions and 
exploitation of natural resources), social (e.g., impact on labor and food security) and economic sustainability (e.g., productivity, costs and agriculture as a subsistence economy) [11,32,49-52], among others.

\section{Materials and Methods}

To achieve our goal, we use the PICOC protocol and SciMAT software to perform a Bibliometric Performance and Network Analysis (BPNA). PICOC ensured the robustness and definition of the research criteria, while SciMAT helped identify the strategic themes, the thematic evolution structure and the main challenges and opportunities in the field of study.

\subsection{PICOC protocol}

The PICOC protocol was used to define the research questions [53], the key terms and variants [54], and inclusion and exclusion criteria for the selection of papers related to the field of study [55]. This method ensures the quality and reproducibility of the research with the lowest bias from the researchers. In this study, the process of the PICOC protocol was adapted by the steps presented by Bruzza et al. (2017) and Silva et al. (2020) [55,56]. Table 1 present the attributes according to the PICOC protocol.

Table 1. Steps according to the PICOC protocol.

\begin{tabular}{cc}
\hline Attributes & Description \\
\hline Population $(\mathrm{P})$ & Define keywords, search terms and variants related to DA. \\
\hline Intervention $(\mathrm{I})$ & Define the documents inclusion and exclusion criteria. \\
\hline Comparison $(\mathrm{C})$ & The approach was a bibliometric performance and network analysis. \\
\hline Outcome $(\mathrm{O})$ & The outcomes are the strategic diagram, and the evolution map of DA. \\
\hline Context $(\mathrm{C})$ & The future of DA is discussed through the main challenges and opportunities. \\
\hline
\end{tabular}

With the support of the PICOC protocol we defined three research questions (RQ1-3):

RQ1: What are the strategic themes related to digital agriculture?

RQ2: How is the thematic evolution of digital agriculture over time?

RQ3: What are the main challenges and opportunities of $D A$ ?

\subsection{Network Analysis and Dataset}

After defining the $R Q$, the criteria for assessing quality were defined. The search string, database, inclusion and exclusion criteria and bibliometric software used are present in Table 2. Then, the documents identified through the execution of the PICOC protocol were inserted in the SciMAT software for BPNA. The search terms used were mentioned in previous research $[11,57,58]$ to represent DA, and were used to cover more related studies 
Table 2. Quality assessment criteria.

\begin{tabular}{cc}
\hline Quality assessment & Description \\
Search string & $\begin{array}{c}\text { ("agriculture 4.0" OR "digital agriculture" OR "digital farming" OR "smart } \\
\text { agriculture" OR "smart farming" OR "precision agriculture" OR "precision farming" } \\
\text { OR "agri-food 4.0") }\end{array}$ \\
\hline Database & Web of Science \\
Inclusion and & Only documents with the search terms present in the title, abstract or keywords \\
exclusion criteria & Related or applicable to digital agriculture \\
& Only documents in English \\
& Articles published over all time \\
\hline Bibliometric software & Science Mapping Analysis Software Tool (SciMAT) \\
\hline
\end{tabular}

For bibliometric analysis and identification of strategic themes and the evolutionary map of the field, we used the SciMAT software developed by Cobo et al. (2012) [30]. We chose the SciMAT because it assists all stages of scientific mapping, bibliometric performance and network analysis, from data preprocessing to the generation of maps of the field of study $[30,52,59,60]$. With the support of the SciMAT, we plotted a strategic diagram and the intellectual network structure of the most important themes [61-63]. Also, it was possible to generate an evolutionary diagram that presents the most important themes of the field of study distributed over time. Figure 1 presents an example of the strategic diagram (a), thematic network structure (b), and thematic evolution structure (c), where the size of the clusters represents the number of associated documents and the importance of the theme for the research field, and the thickness of the lines represents the strength of the relationship between clusters $[30,59,60]$. The evolutionary map was created based on the equivalence index, where the solid lines (Figure 1 (c)) indicates that the clusters share the main theme (main theme $\in$ \{thematic nexuses\}), while dashed lines represent a connection between non-main elements (main theme $\notin$ \{thematic nexuses\}), and the absence of lines means that the theme was discontinued from one period to the next [64].

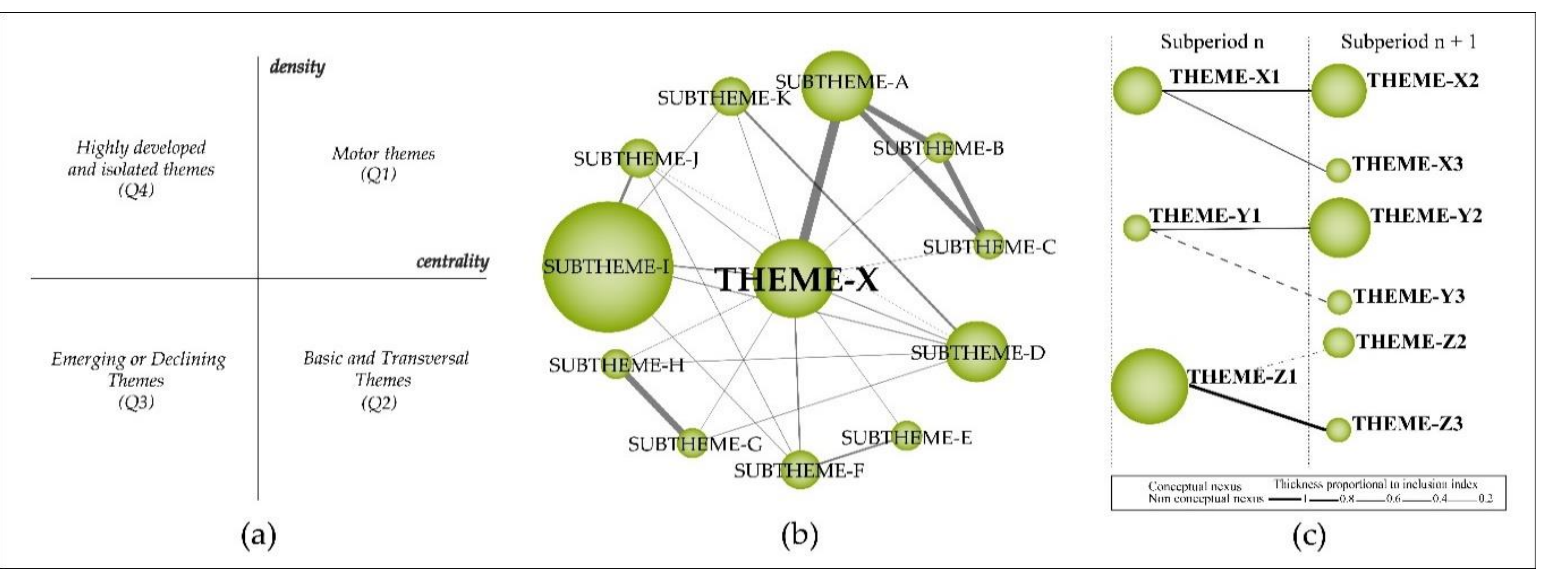

Figure 1. (a) Strategic diagram; (b) Thematic network structure; (c) Thematic evolution structure.

For analysis, we used the Web of Science as it is an indexed database with a greater quality of research available [65]. The data were extracted from the database on September 21, 2020. Altogether, 4,701 documents were exported from the Web of Science and 7 duplicate documents were removed. Using SciMAT software, 14,700 keywords related to the documents were identified and inserted into preprocessing step. Then, keywords with the same meaning were grouped, such as 'GEOSTATISTIC' and 'GEOSTATISTICS', and 'INTERNET OF THINGS' and 'IOT', and meaningless or generic words have been removed, totaling 13,935 clusters of words. After preprocessing the data, they were inserted in a period to generate the strategic diagram of the field of study, and later divided into three subperiods (1994 - 2011; 2012 - 2017; 2018 - 2020) to generate the evolutionary map. In this way, it was possible to identify from the first document published in Web of Science that discusses PA and the evolution of the field until the emergence of A4.0 in 2011 (1994 - 2011). The second subperiod (2012 - 
2017) presents the evolution of DA after the emergence of the A4.0 concept, and the use of new technologies in agriculture. Finally, the third subperiod (2018 - 2020) presents the most relevant themes today and provides valuable insights about the future of the research field.

After defining the subperiods, we generate the diagrams based on the keyword co-occurrence matrix with the SciMAT to identify the most important themes and their nodes with other clusters [66-68]. Then, to identify the similarity between themes, the data were normalized using the Equivalence Index [69], and then clustered based on the Simple Centers Algorithm to create a network of relationships [70]. To create the diagrams, we reduced the data on a frequency reduction of eight times and defined a maximum and minimum network of 12 and 3, respectively, in order to plot only the most important clusters of the field of study. The clusters were plotted on a twodimensional diagram with four quadrants (Q1-4) (e.g., Figure 1 (a)) whose horizontal axis represents the centrality of the themes and their number of connections with other themes, and the vertical axis represents the density of the connections between clusters $[11,13,59,60]$. The four quadrants are defined as that:

- Motor themes (Q1): the upper right clusters are highly developed themes. The strong centrality and density represent the high number of associated documents and the great number of links between these themes with others.

- Basic and transversal themes (Q2): clusters in the lower right quadrant are themes that have many relationships with other themes, but whose relationships are weak.

- Emerging or declining themes (Q3): represents clusters with few and weak links with other themes, and which may be appearing or disappearing in the field of study.

- Highly developed and isolated themes (Q4): the upper left quadrant are composed of clusters with low centrality and high density. These clusters have few but strong links with other themes.

The motor themes of the strategic diagram (Figure 1 (a), Q1) were explored to identify the relationships with other themes. In this way, it was possible to identify technologies, techniques and other subjects widely discussed, as well as the main challenges, opportunities and enablers of DA.

\section{Results}

To explore in-depth the DA field, we present a BPNA, which includes the performance in terms of productivity overtime and journal, the strategic themes (Figure 3), the thematic network structures of the motor themes (Figure 4), and the evolutionary map of the field (Figure 5). This analysis allows us to understand the transformations in agricultural production techniques, and the impact on sustainability, organizations, and society.

\subsection{Bibliometric performance analysis of $D A$}

In 1994 the term PA started to be widely discussed in studies that evaluated the rate of application of inputs in crops [71], the spatial and temporal variability of crops [72-74] and the potential of precision techniques for conserving natural resources [75]. After the initial fuse, the field of study has continued to grow and new concepts have emerged over time. In 2011, with the emergence of Industry 4.0, the term A4.0 came up with wide scope for the adoption of digital technology in agriculture and to represent the creation of a value chain [11,32].

Figure 2 shows the number of studies published over time, and highlights the importance and expansion of the field of research. In 1994, only 5 articles related to DA were published, in 2017 the number reached 374 articles, and 762 studies were published in 2019. In 2020, the decrease in publications is justified by the date of data collection (September 21, 2020). 


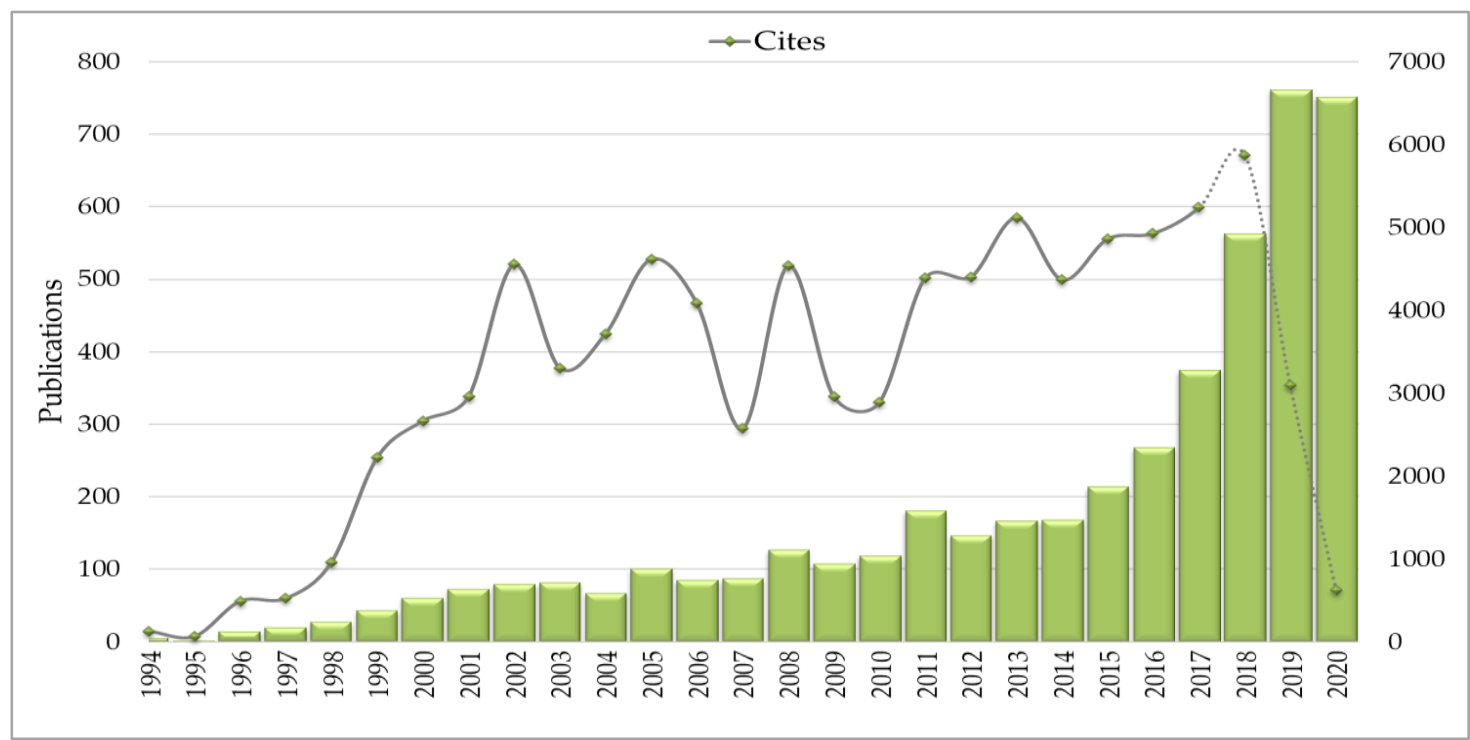

Figure 2. Publications over time (1994 - September 21, 2020).

Table 3 presents the Journals and authors that most published studies related to DA indexed in Web of Science in the period from 1994 to September 21, 2020 and based on the search string used. The most productive journal is the Computers and Electronics in Agriculture with 407 documents, followed by Precision Agriculture (231) and Sensors (187). The authors with the greatest number of studies related to the theme are Sudduth, K. A. with 46 documents, Lopez-Granados, F. (36) and Shearer S.A. (31).

Table 3. Most productive Journals and authors.

\begin{tabular}{ll|lc}
\hline Most productive Journals & Doc & Most productive authors & Doc. \\
\hline Computers and Electronics in Agriculture & 407 & Sudduth, K. A. & 46 \\
Precision Agriculture & 231 & Lopez-Granados, F. & 36 \\
Sensors & 187 & Shearer, S.A. & 31 \\
Remote Sensing & 171 & Schmidhalter, U. & 21 \\
Applied Engineering in Agriculture & 101 & Ribeiro, A. & 21 \\
Transactions of Asabe & 87 & Bareth, G. & 17 \\
Biosystems Engineering & 71 & Miao, Y.X. & 16 \\
Geoderma & 70 & He, Y. & 15 \\
\hline
\end{tabular}

\subsection{Strategic Diagram}

The Strategic Diagram (Figure 3) present 22 clusters distributed in four quadrants of the twodimensional diagram, of which 9 are motor themes (Q1), 2 are basic and transversal themes (Q2), 8 are emerging or declining themes (Q3), and 3 are highly developed and isolated themes (Q4). The size of each cluster is proportional to the number of associated documents, the horizontal axis represents the links from one cluster to others (centrality), and the vertical axis demonstrates the strength of these links (density). The table in Figure 3 shows the core documents, h-index, cites, centrality (C), and density (D) of each theme. 


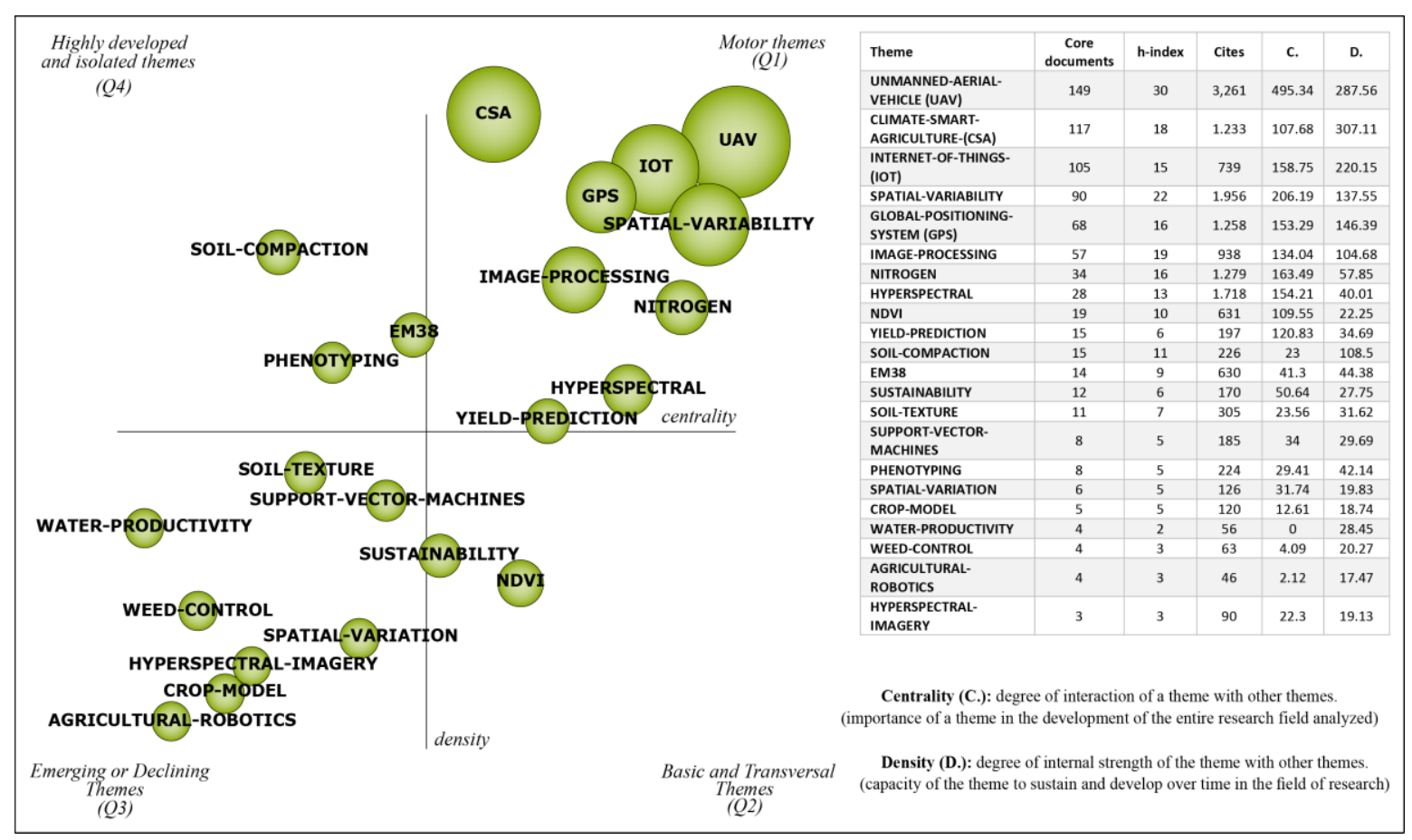

Figure 3. Strategic diagram ad performance analyzes.

The 'UAV' (Unmanned Aerial Vehicle) cluster contains the largest number of associated documents, and it is the most expressive theme in terms of h-index, cites and centrality, highlighting this cluster as one of the most discussed theme in the literature. The cluster 'CSA' (Climate-smart Agriculture) also have an expressive core documents, and is the first ranked in terms of density, but its low centrality shows that the relationship between CSA and other themes is still underexplored. Other clusters that stand out are 'IOT' (Internet of Things), 'SPATIAL-VARIABILITY', 'GPS' (Global Positioning System), 'IMAGE-PROCESSING', 'NITROGEN', 'HYPERSPECTRAL' and 'YIELDPREDICTION' (Figure 3). These motor themes (Q1) are explored in depth through the thematic network structures in the next subsection.

Besides, 'NDVI' (Normalized Difference Vegetation Index) and 'SUSTAINABILITY' appear like basic and transversal themes (Figure 3), and represent the concern for the sustainable development of agriculture. Other techniques appears related to crop management such as 'WEED-CONTROL', 'CROP-MODEL', 'SOIL-TEXTURE', 'PHENOTYPING', 'SOIL-COMPACTION' and 'WATERPRODUCTIVITY', and others related to technologies such as 'AGRICULTURAL-ROBOTICS', 'HYPERSPECTRAL-IMAGERY', 'SUPPORT-VECTOR-MACHINES' and 'EM38'. Although some clusters represent specific analyzes and techniques related to productivity and quality of agricultural production, the motor themes highlight the way of agriculture and the transformation expected for food production in the coming years.

\subsection{Motor themes related to $D A$}

We explore the thematic network structure (Figure 4) of the motor themes presented in the strategic diagram (Figure 3). This analysis highlights the relationships of a cluster with others and provides an in-depth view of the field of research. The size of each cluster is proportional to the number of associated documents, and the thickness of the lines denotes the binding force between clusters. 

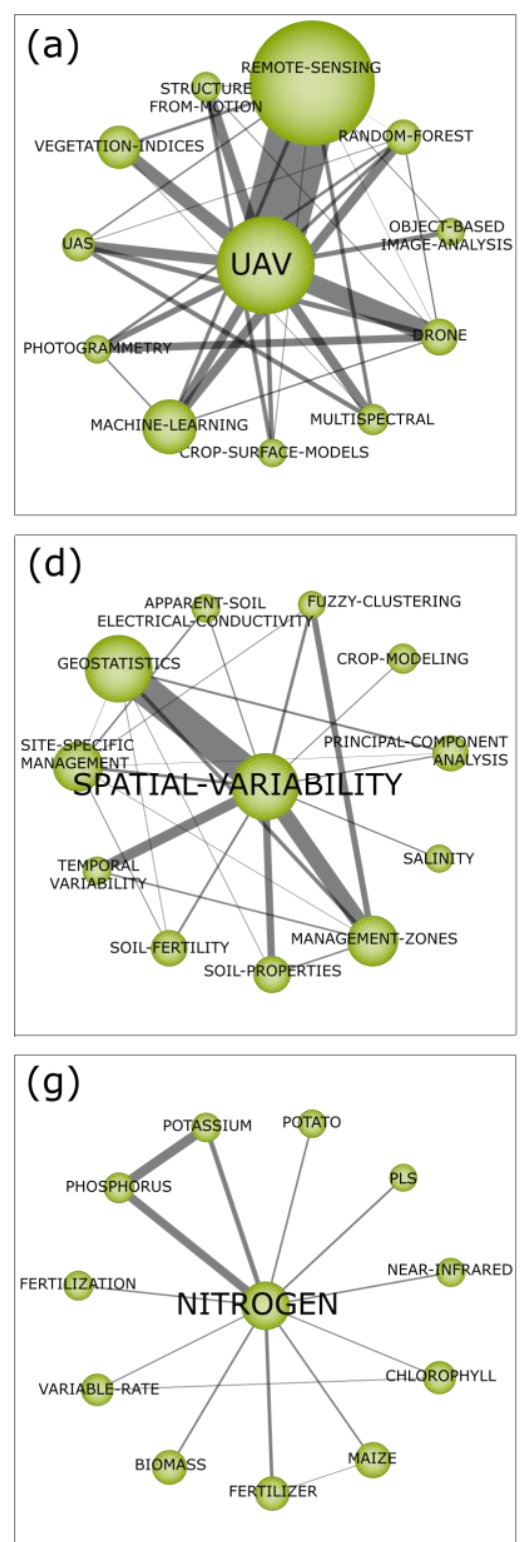
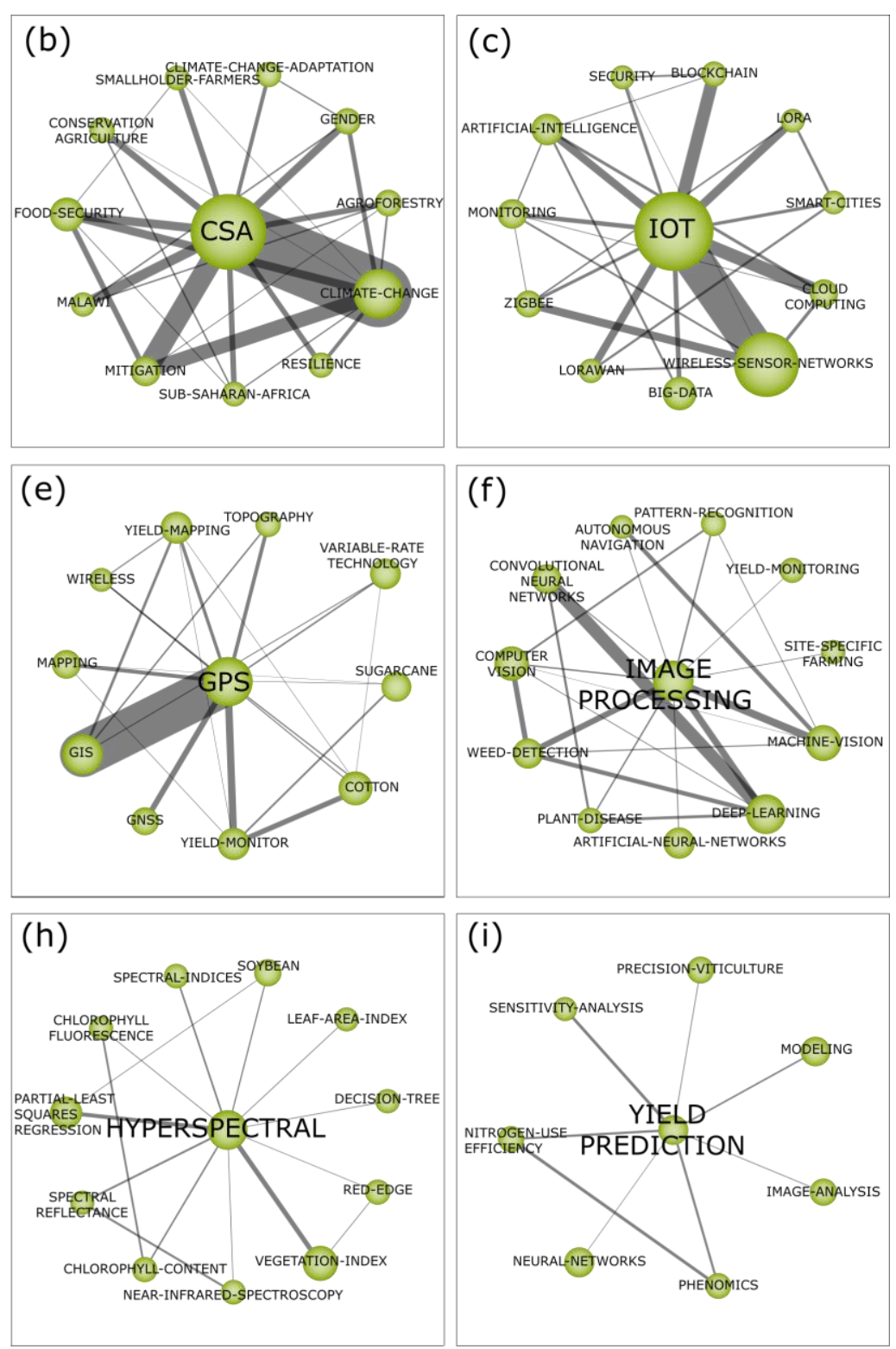

Figure 4. Thematic network structures. (a) UAV; (b) CSA; (c) IoT; (d) Spatial Variability; (e) GPS; (f) Image Processing; (g) Nitrogen; (h) Hyperspectral; (i) Yield Prediction.

\subsubsection{Unmanned Aerial Vehicle (UAV)}

The cluster 'UAV' (Figure 4 (a)) presents prominent importance in the strategic diagram (Figure 3) due to its high degree of interaction with the other motor themes. The UAV, commonly known as a drone [76], corresponds to a pilotless aircraft, i.e. a flying machine operated with no humans (passenger/pilot) onboard [77]. UAVs are low-cost and easy-to-operate technologies in agriculture [78] that can be adopted for spraying in fields [79], such as water precision irrigation. Given the technological advancement emerging in different countries, UAVs have been gaining more and more space and importance for smart farming [76,78]. Different sensors can be coupled to UAVs [76], which demonstrates the strong relationship between UAV and the subtheme 'REMOTE-SENSING', followed by the subthemes 'MACHINE-LEARNING', 'VEGETATION-INDICES' and 'DRONE', among others (Figure 4 (a)).

The sensors in the drones can generate vegetation indices, helping to monitor crop growth diagnosis and grain yield prediction [80]; disaster detection in environmental areas [81]; the existence of pests and pathogens in the crop; the analysis of the health and stress status of the vegetation; and the assessment of soil fertility for appropriate remote management and precise and reduced 
application of agrochemicals, driving sustainable agriculture [76] and increased productivity. On this, machine learning improves decision-making on precision and digital agriculture, such as the prediction of nitrogen index of the crop through remote sensing from UAV $[78,82]$. Thus, farm's data and information easily collected through drones, such as images [83], can generate knowledge from machine learning techniques to make agriculture precise and digital. Zhang and Zhao (2019) [84] used images of coastal soils captured through UAV to identify salinization levels, and then proposed a method to improve the monitoring and management of the soil for avoiding the negative impacts of salinization on crop growth and production. Hence, this cluster highlights the central role of UAV, which, together with other emerging technologies, generates precision in agriculture and enables the interconnection among technologies for better decision-making, allowing farms to be smart.

\subsubsection{Climate-smart Agriculture (CSA)}

CSA (Figure $4(\mathrm{~b})$ ) is a concept related to the adoption of best agricultural production practices and methods for reorienting agriculture for environmental protection, food security and climate change issues $[15,85]$. The population increase, land and environmental degradation, and the negative impacts of the food system on the climate require new agricultural practices. In this frame, CSA is an extremely necessary approach to find win-win solutions for the sustainable development of agriculture [86]. Climate change and the degradation of the planet's biodiversity cause risks to food supply, and the vulnerability of people who have agriculture as their main source of subsistence [15]. To deal with this, the resilient agriculture proposed by CSA seeks to create adaptive coherence between climate and agricultural practices [86]. To assist in the development of CSA, farmers embrace technological innovations that could make agriculture more sustainable. However, great governmental and academic incentives need to be dedicated to this area to assist the agricultural sector in sustainable development $[85,86]$.

This high-density motor theme is related to sustainable agriculture, which shows its strong relationship with climate-related themes (e.g., 'CLIMATE-CHANGE', 'CLIMATE-CHANGEADAPTATION'), environmental preservation (e.g., 'AGROFORESTRY', 'CONSERVATIONAGRICULTURE'), organizations (e.g., 'SMALLHOLDER FARMERS') and discussions related to agricultural resilience, food security and the main challenges for organizations, especially for smallholders. Related research discusses technological adoption [87], farmers' adaptation to resilient agriculture [88], economic models [89], ways to increase the resilience of smallholder farmers [90], and the impact of CSA on food security [91], among other issues associated with resilient agriculture.

\subsubsection{Internet of Things (IoT)}

The cluster 'INTERNET-OF-THINGS (IoT)' (Figure 4 (c)) has a high degree of interaction with the subtheme 'WIRELESS-SENSOR-NETWORKS', followed by 'BIG-DATA', 'ARTIFICIALINTELLIGENCE', 'CLOUD-COMPUTING' and others. IoT can be defined as a grouping of technologies and infrastructures that, wirelessly connected, enables data mining from interconnected objects, as well as the monitoring and correct management of data [11,92]. It allows remote access and control of objects [93]. Thus, IoT has been achieving a prominent role in agriculture. Both the quality and quantity of production in the agricultural industry have been maximized through IoT [94], such as crop yield and efficiency [95]. IoT technologies, such as smart sensor networks, cameras, weather stations and smartphone applications can improve data collection from crops and decisionmaking for smart farm management [96].

There are many ways of adopting IoT in agriculture. Jin et al. (2020) [97] proposed a predictor for weather based on IoT to an accurate prediction of temperature and humidity in fields, allowing anticipated planning and control for sustainable precision agriculture. Jayaraman et al. (2016) [96] proposed an IoT platform capable of expanding the collection of data on soil, irrigation, fertilization and environmental conditions, generating relationships among data for forecasting crop performance and boost smart farming. Relating IoT to blockchain, Hussain (2019) [98] developed a model capable of helping in the migration from traditional to smart agriculture. Tekinerdogan (2018) [3] used IoT to develop a portable agricultural sensor network system, which collects data (temperature, light intensity, and soil moisture content) using sensors and a microcontroller to generate databases that can be used through Big Data for better crop management. These IoT actions can be maximized when 
combined with artificial intelligence technologies, which facilitate the management of data collected from different objects in the field [93]. Besides, connectivity on DA through IoT becomes efficient and effective when based on cloud computing [99]. Thus, regardless of the application, IoT actions in agriculture require investments in cloud computing to facilitate the collection, storage, access, and management of integrated data. Therefore, this cluster emphasizes the importance of IoT as a link among different technologies, tools, equipment, and machines that jointly improve precision agriculture and, consequently, lead to digital agriculture. This technological transformation also highlights the need for digital innovation ecosystems, capable of integrating government, companies and universities for the development of digital, profitable and sustainable solutions.

\subsubsection{Spatial Variability}

The cluster 'SPATIAL VARIABILITY' (Figure $4(\mathrm{~d})$ ), is a motor theme that presents strong interaction with the subthemes 'GEOSTATISTICS', 'MANAGEMENT ZONES', 'SITE SPECIFIC MANAGEMENT', 'SOIL PROPERTIES' among others. Therefore, this cluster in linked with the increase efficiency and crop productivity. The information obtained through 'MANAGEMENT ZONES', for instance, contributes for monitoring soil properties at agricultural sites. This is a key factor for increase food production [100] and farmers' economic returns [101]. The mapping of soil heterogeneity have been contributing for the use of 'MANAGEMENT ZONES' and 'GEOSTATISTICS' as tools in agricultural management [102]. Some studies shows that farmers, through GPS, visualize the information of DA made by georeferenced analysis [103].

\subsubsection{Global Positioning System (GPS)}

Through georeferencing, GPS was one of the first big steps towards DA. The cluster 'GPS' (Figure $4(\mathrm{e})$ ) is a motor theme that presents strong interaction with the subtheme Geographic Information Systems (GIS). Other subthemes, such as 'YIELD-MONITOR', 'YIELD-MAPPING' and 'VARIABLE-RATE TECHNOLOGY' also have prominence link with this cluster. Thus, the integration of GPS with other smart technologies such as GIS and remote sensing can boost farming productivity and cost efficiency [104]. GPS corresponds to a navigation system that, using satellites, identifies the exact position and velocity of an object around the world and can guide directions [105]. Agricultural activities, such as seeding and ploughing, can only be precisely by means of vehicle navigation accuracy [106].

In previous research, $\mathrm{Si}$ et al. [106] proposed a method to improve the accuracy of the steering angle of agricultural vehicles by combining GPS with the low-cost Micro-electromechanical System (MEMS), which improves DA. Palaniswami et al. [107] argue that the joint adoption of GPS and GIS technologies can improve the cultivation of sugarcane in coastal lowland ecosystems, making production precise and sustainable. Khosro (2018) [108] developed a strawberry yield-monitoring picking cart, equipped with a real-time kinematic global positioning system (RTK GPS), different types of sensors, a microcontroller, and an inertial measurement unit to improve the synchronization of the carts with robots in harvesting and creating yield mapping of strawberry productivity. Commonly, yield mapping on farms is performed using GPS and variable rate technology for boosting planters' performance [109]. Also, Thrikawakaa et al. [110] demonstrate that the application of variable rate technology through GPS in agricultural vehicles improves the water content in fields and reduces the application of fertilizers. Thus, this cluster highlights the role of GPS as a leading technology capable of improving the effectiveness of DA through its capacity of interconnection with other smart technologies. Emerging technologies combined with scientific knowledge make it possible to use the strategic geographical location of agricultural production, helping to make precise and targeted decisions.

\subsubsection{Image Processing}

The cluster 'IMAGE PROCESSING' (Figure 4 (f)) presents strong linkages with agricultural management tools (e.g., 'MACHINE VISION' and 'COMPUTER VISION') that provide data for the farmer's decision-making. Zhao et al. [111] used machine vision for providing color images for the detection of immature green citrus. The use of video processing (i.e., machine vision) also was 
analyzed by Sabzi et al. [112] to classify potato plant and three types of weed. In this regard, machine vision also was revised by Wang et al. [113], combined with image processing as relevant tools for 'WEED DETECTION'.

Machine learning algorithms also are linked with image processing and provide 'DEEP LEARNING' in agriculture [114]. The use of 'ARTIFICIAL NEURAL NETWORKS' is an example of AI method [115] to create new forms to solve agricultural complex problems that are based in big data. Through image processing, several outputs provide by machine learning are showed in apps for smartphones and computers [116].

\subsubsection{Nitrogen}

The cluster 'NITROGEN' (Figure 4 (g)) likewise the 'HYPERSPECTRAL' and 'YIELD PREDICTION' clusters have no stronger relation with some themes as the others clusters. As an important nutrient for agricultural production, this cluster is related to crop management (e.g., 'MAIZE' and 'POTATO'), and fertilizers (e.g., 'PHOSPHORUS' and 'POTASSIUM'). The link between 'NITROGEN' and these themes comprise several fields of studies such as nitrogen deficiency [117], nutrient management [118,119], nutrient loses [120], nutrient efficiency [121], and nutrient monitoring [122]. Therefore, the technical agronomic backdrop is preeminent in this cluster. In addition, this theme is strongly linked to efficiency (such as application in variable-rate) in the application of nitrogen $[118,119,123]$.

\subsubsection{Hyperspectral}

Several technologies are being developed and tested to analyze plants, soil and crop variables, such as optical sensors, three-dimensional (3D) imaging, fluorescence imaging, thermography, multispectral and hyperspectral imaging [124]. The 'HYPERSPECTRAL' cluster (Figure 4 (h)) shows that these analyzes are standing out in agriculture, mainly because hyperspectral imaging is a more advanced technique than traditional multispectral imaging, and allows the identification of more details of the target features [125]. Hyperspectral images are used as an efficient alternative for collecting and processing data and creating an electromagnetic spectrum of agricultural fields, being a useful tool for monitoring, analyzing, and more accurate detection of spatio-temporal variations of crop physiological and morphological characteristics [125,126] such as soil attributes and soil degradation.

Despite its great potential, hyperspectral images is still little used outside the academic context, but this is changing through low-cost and mini-sized airborne hyperspectral technologies that are being used by farmers [125]. This difficulty occurs due to the complexity of technologies and algorithms, and the need to store and transfer data collected by hyperspectral analysis devices [127]. The significance of the 'HYPERSPECTRAL' cluster shows the volume of analyzes performed using maps and images of crops. The clusters associated with this theme demonstrate analyzes related to vegetation indexes and characteristics (e.g., 'VEGETATION-INDEX', 'CHLOROPHYLL-CONTEXT', 'CHLOROPHYLL-FLUORESCENCE' and 'LEAF-AREA-INDEX'). Previous research used hyperspectral remote sensing to measure grapevine drought stress [128], identification of pests and diseases [129], and for assessing seed germination [130].

\subsubsection{Yield prediction}

Yield prediction is historically used in agriculture for farmers to plan inputs, labor, profitability and other issues related to agricultural productivity. The cluster 'YIELD-PREDICTION' (Figure 4 (i)) in DA represents the evolution of predictive analysis on crop yields, which in the past was carried out by the knowledge of farmers, and is now carried out with emerging technologies [89]. In this way, preharvest crop yield prediction helps farmers to make better and faster decisions related to planting, fertilization, irrigation, pruning and harvesting plantations [131], also contributes to the entire supply and consumption chain, and allows the projection of future scenarios for food production [132].

This cluster appears related to few themes, but among it we can highlight 'MODELING', 'IMAGE-ANALYSIS' and 'NEURAL-NETWORKS' used to map and model crop data and 
information for future predictions. Previous research related to crop yield prediction used different techniques and technologies to collect and analyze data, such as Neural Network Techniques [91], Unmanned Aerial System Imagery [133], Airborne Optical Sensors [134], Artificial Neural Networks [135], Machine Learning [136-138], Hyperspectral Imagery and Ensemble Learning [139], among other.

\subsection{Thematic evolution structure}

The evolutionary map presents the themes that have stood out over time. The map was divided into three subperiods to show the most important themes according to the evolution of the field of study. The first subperiod presents the main themes studied since the first mention of the term PA in 1994 in Web of Science until the emergence of the Industry 4.0 concept in 2011 and, consequently, the emergence of the A4.0 concept. The second subperiod covers the years 2012 to 2017 and highlights the terms widely discussed since the appearance of A4.0. The last subperiod (2018 - 2020) highlights the most current and relevant terms in the literature in the last years. Figure 5 shows the evolutionary map of the field of study, the size of the clusters is proportional to the number of associated documents, while the thickness of the lines represents the relationship between the themes. Continuous lines represent conceptual nexus and dashed lines have non-conceptual nexus.

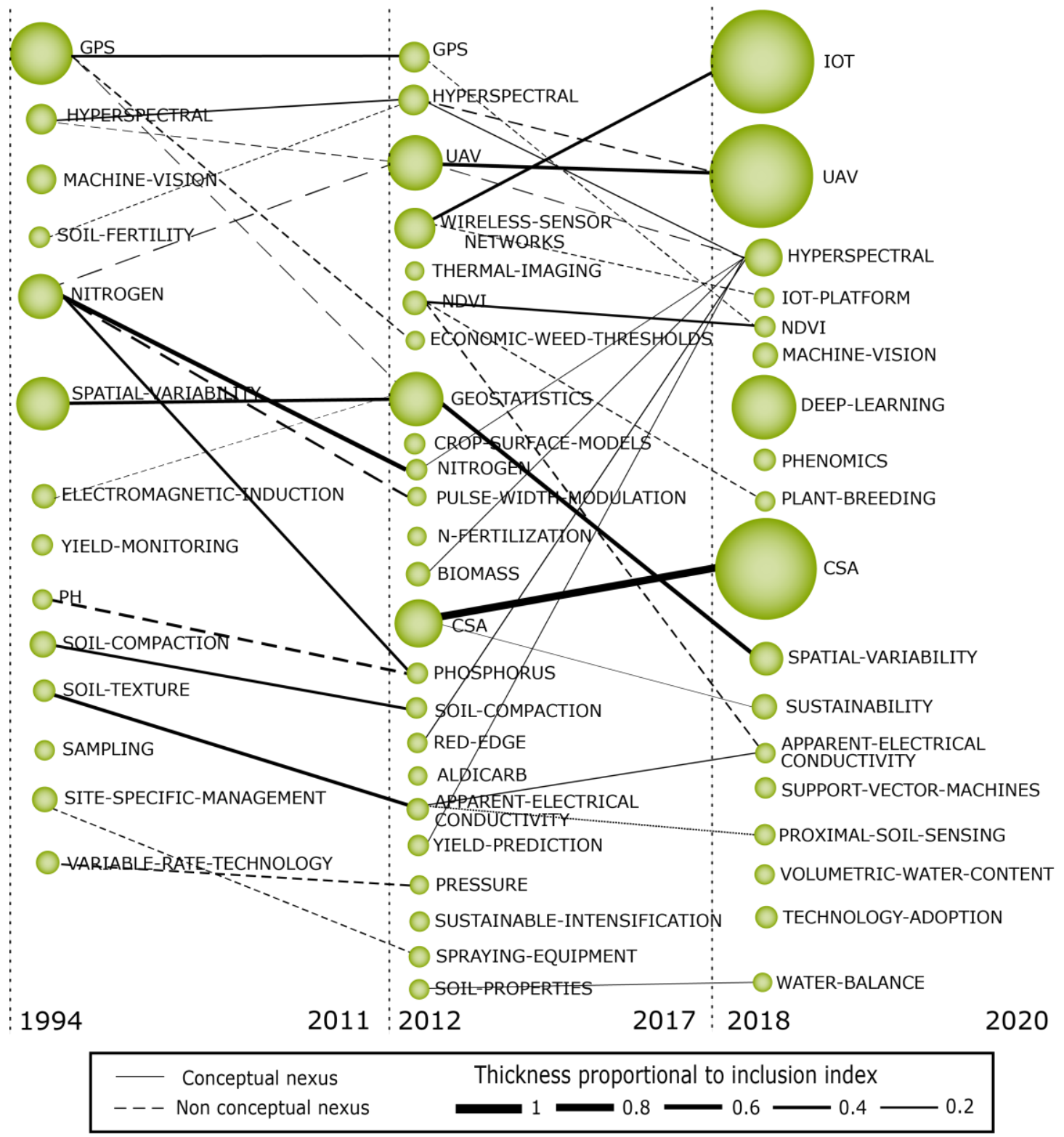

Figure 5. Thematic evolution structure. 
In this subperiod (1994 - 2011) (Figure 5), we identified the first studies that mentioned DA through discussions about the use of technologies to increase productivity, deal with environmental variability and environmental conservation of agribusiness [71-75]. This subperiod contains studies that used hyperspectral maps to analyze vegetation indices [140,141], imaging techniques [142] and geostatistical analysis [143]. Besides, Figure 5 shows that technologies started to be explored at this time such as 'GPS', 'HYPERSPECTRAL' images, and specific analyzes of soil and plants such as 'SOILFERTILITY', 'NITROGEN', 'ELECTROMAGNETIC-INDUCTION', 'PH', 'SOIL-COMPACTION' and 'SOIL-TEXTURE'. In general, these themes show that few technologies were discussed and most of the themes were associated with crop variability. These themes prove that the discussions associated with DA mainly represent the use of technologies such as georeferencing to analyze variability associated with soil and plants.

In this subperiod, the first discussions on agroecosystems were developed [144] to create strategies to mitigate damage to the environment. It is important to note that this subperiod was one of the most important for discussions related to sustainability, as the research was guiding for other in-depth studies aimed at the development of resilient agriculture and the sustainable development of agribusiness. In addition, many studies in this subperiod predicted that DA would be the future of agribusiness [145-150].

\subsubsection{Second subperiod (2012 - 2017)}

The second subperiod (2012 - 2017) (Figure 5) was characterized by a greater number of documents associated with the consolidated PA motor themes and with emerging A4.0 ones, as new technologies started to be discussed as the application of UAV [151], 'WIRELESS-SENSORNETWORKS' and 'NDVI'. Clusters still related to the first subperiod such as 'NITROGEN', 'HYPERSPECTRAL' and 'GPS' demonstrate that some themes have remained strong over time. In addition, new themes emerged such as 'GEOSTATISTICS' with a significant number of documents, and 'SUSTAINABLE-INTENSIFICATION' and 'CSA' associated with the development of resilient and sustainable agriculture, demonstrating the expansion of the field of study [152-154].

Between 2012 and 2017 the term A4.0 gained space and came to be widely discussed in the literature to portray the creation of a digital value chain in agriculture. Although many terms are discussed in this subperiod, few of them stand out in the volume of associated documents and interrelationships with themes from other subperiods. Only the 'GEOSTATISTICS' theme has a strong relationship with the 'SPATIAL-VARIABILITY' clusters of the first and third subperiods, highlighting the potential of geostatistics for analyzing crop variability. Also, 'CSA' evolves to become one of the main themes of the third subperiod. It is important to note that some themes have evolved over time, however, the small size of most clusters shows that the field of study was still under development.

\subsubsection{Third subperiod (2018 - 2020)}

The third subperiod (2018 - 2020) (Figure 5) presents the most recent themes related to DA. Three clusters stand out with a large volume of associated documents, they are 'IoT', 'UAV' and 'CSA', which indicates that the use of emerging technologies and sustainable development is currently the most important concerns of researchers in the primary sector. The 'IoT' and 'UAV' clusters show the potential and adaptability of small sensors for any agricultural scenario, whether in large crops or in mountainous areas that are difficult to cultivate [11], while the 'CSA' cluster shows that concern for the sustainable development of agriculture continues to grow and is characterized as one of the most important discussions for smart agriculture [88,91]. In addition, discussions related to 'DEEPLEARNING' and 'MACHINE-VISION' represent technological adoption in agriculture, and themes like 'APPARENT-ELECTRICAL-CONDUCTIVITY' [155], 'WATER-BALANCE' [156] and 'PROXIMAL-SOIL-SENSING' [157] show that the concern with analyzes of plants and soil remains extremely important for the digital transformation of agriculture.

A broad look allows us to see the evolution of the field of study and the main themes discussed over time. The third subperiod also produces insights into future trends, because some themes stand out from the others and should remain important. Besides, other themes emerged only in the last subperiod, and may represent emerging themes that can be further explored in depth in the coming 
years. The growth in the number of documents in the field of study (Figure 2) and discussions associated with technological adoption (Figure 4) demonstrate the commitment of researchers to the development of the primary sector and its importance for the sustainable development of society and organizations.

\section{Challenges and Opportunities}

\subsection{Main challenges}

There are many challenges related to the adoption of emerging technologies in agriculture, such as variations in soil, climate, cultivated species and producer size. Government investments, export volume, agricultural and consumer culture are also factors that directly impact the way food is grown, and the efforts and investments dedicated to production. Developed and emerging countries have different types of government investment for agricultural production and some are developing projects aimed at the digital transformation of agriculture in countries like China [158], Brazil [159], Mexico [160], Thailand [161,162] and others.

Among the main challenges of digital technology adoption are the characteristics and peculiarities of emerging technologies, which are often complex for the little technological knowledge of farmers [45]. The largest volume of agricultural production is from developing countries, and most of its farmers are small producers with low education. Under these circumstances, even the language can become a barrier to technological innovation, since most technologies are developed in English, a language not spoken by small producers in emerging countries [31]. This barrier for small producers favors large agribusiness companies that have workers trained to use technologies and apply them to increase the quality of large-scale production. In addition, there is a major digital infrastructure problem in many developing countries, which are gradually developing ways to bring digital devices and applications at low cost to small producers to increase profitability and production quality.

Technological advances bring complex issues related to data security and privacy. Concerns about information, confidentiality and data integrity are major challenges that concern farmers [163]. In highly technological scenarios, these concerns increase the efforts of researchers and practitioners in the search for better encryption and security techniques to reduce the risks of cyber-attacks and ensure data security and privacy [164]. According to Zhang et al. (2020) [165] farmers are insecure about data security, as well as the physical requirements for equipment and effective tools for data protection and distributed systems for agricultural management. Hussein (2019) [164] reinforces the care with the computational structure necessary for cloud storage to be effective and secure. These surveys highlight the concern with data security, confidentiality and reliability to guarantee fair competition and economic development. In this sense, two strands of challenges can be considered: the first is about technical challenges, such as the mastery and the adaptation of technological tools in order to direct them in the best possible way for optimal gains. The second aspect is related to sustainability issues such as the continuous world population growth and global warming (be it due to the greenhouse effect, gas emissions, etc.) and its harmful effects to agriculture [166].

Although many authors discuss the technological potential for promoting sustainable development, other authors discuss the paradox of sustainability [167] by raising questions about the contradictions between economic growth and sustainability that mainly affect the low-income population [168]. In the same perspective, the technological paradox discusses the lack of evidence about technological benefits in the productivity and sustainability of organizations and society [169]. These controversies between authors show that discussions about these paradoxes in agriculture are not yet sufficiently developed and future research could explore this topic in-depth [52].

\subsection{Opportunities}

The primary sector is crucial for human survival and full of challenges, and in this scenario, the technological potential can be exploited to meet the food needs of the human population without damaging the environment [52]. The number of studies associated with sustainable agriculture shows that technological adoption has great potential to assist in the development of a resilient agriculture that integrates the economic, environmental and social pillars of sustainable development. Previous 
research on CSA explored the adaptation of agricultural methods to develop adaptive agriculture for plantations, landscapes and forests, while addressing climate issues and food security [85,86]. Regenerative and circular agriculture explores ways to avoid the use of chemicals, and ways to develop natural processes to protect the soil, the environment and people through the production of healthier foods [170]. According to Ofori and El-Gayar (2020) [31] the main drivers for technological adoption in agribusiness are related to governance, policies, trade opportunities, effects on human capital, employment opportunities and environmental protection. In this perspective, traditional agriculture is no longer sufficient to meet the demand for food, quality, sustainability and protection of the environment, and a new paradigm is needed, the technological paradigm [171].

Advances in agricultural production are crucial for increasing production and improving logistics performance and traceability of agricultural data in the coming years [52]. Although big machines favor agricultural monopolies, small technologies such as sensors, actuators and drones can be developed at a lower cost and with features to assist small farmers in the collection and analysis of crop variability data [11]. Other technologies such as smart grid can assist in the development of integrated energy networks that facilitate the management of crops at lower costs [172]. DA depends on technological progress, and a viable path for future research concerns strategic forecasting [173] and analysis of innovation capabilities [174,175] to develop technological innovations in smart agriculture. The DA can promote changes, evolution and gains, both for society and sustainability, as well as for economic agents through the gains in scale and efficiency of the digitization of agriculture. In this frame, if drones and IoT are more connected to companies and businesses, CSA has an important impact on inclusive and sustainable agriculture. The literature presents several technological solutions aimed at environmental protection and economic and social sustainability, which represent both technological and sustainable revolutions in the primary sector. It may motivate the development of a cycle of sustainable production and consumption to transform the planet and society.

To create a technological and sustainable culture, agriculture depends on the engagement of various members of society, such as universities, farmers, companies, the community and the government. The participation of universities is crucial for the development of technologies and research aimed at modeling and developing methods and techniques that assist farmers in the management of agricultural processes and technologies. Government programs and financing can assist in the digital transformation of agriculture in developing countries, instigating the production and consumption of sustainable products, less waste and awareness of recycling. In this perspective, innovation ecosystems can be explored in-depth for the digital and sustainable transformation of the primary sector. The adoption of new technologies enables the transformation of value chains into digital ecosystems, with the potential to integrate organizations and stakeholders, benefiting each participant in the ecosystem [176]. As in industries, in agriculture, value ecosystems can directly impact economic performance and business agility. To do this, national innovation systems can assist in the transfer of knowledge between industry and universities [177,178], facilitating the development of a digital innovation ecosystem.

Besides, the number of startups focused on agribusiness is growing, and they are developing technologies at a lower cost and that meet the needs of small and medium farmers. These enablers assist the development of small producers, who are responsible for a large portion of the world's population's food production, and who suffer from the challenges of agricultural revolutions. Lean agriculture techniques can be used to optimize agricultural processes and facilitate the adoption of emerging technologies in crops. Technologies such as Big Data facilitate the collection and analysis of large volumes of data, and IoT through its small sensors and actuators can be used in any type of environment. Besides, cyber security can be exploited to address farmers' fear of data protection and security. Together these approaches can facilitate the digital transformation of agriculture in different scenarios and for different sizes of agricultural producers.

\section{Conclusions}

In this research, we present the strategic themes and the scientific evolution structure of digital agriculture. With the support of the PICOC protocol and the SciMAT software was possible to map 
and identify the strategic themes of the field of study, which are mainly associated with technologies and sustainable development such as IoT, UAV, GPS, spatial variability, CSA, and others. Besides, the evolution map divides the literature into three subperiods of time, listing the most important themes at each stage of development of digital transformation in agriculture. The main challenges associated with digital technological adoption were identified, which are mainly related to the complexity of technologies, agricultural culture and adaptation, data security and environmental issues. Also, we identified the main opportunities of technological adoption in agribusiness, that are strongly related to the creation of a technological and smart value chain to increase the productivity, quality and profitability of agricultural production, while promoting economic, social and environmental sustainability. Thus, we cover a gap in the literature related to the evolution of the digitalization of agriculture and its strategic themes over time.

\subsection{Limitations and further research}

Despite its contributions, this research has limitations. This study explored only documents from the Web of Science database and we explore only the thematic structures of the motor themes, and other themes could be addressed in future works. It is important to keep in mind that agriculture directly impacts socioeconomic conditions and environmental sustainability, thus a more comprehensive qualitative analysis could be realized in terms of the implications of DA for sustainability and social development. The role of emerging technologies to promote food security, and the impact of food production on society and organizations need to be explored. Future research can explore in-depth agricultural management practices focused on CSA, sustainable and lean agriculture to identify and analyze sustainable production paths, in addition scenarios and frameworks for smart agriculture implementation could be explored. Future research could yet explore specific research string based on emerging technologies such as Big Data, Artificial Intelligence, blockchain, Internet of Things, autonomous robots and others. Innovation ecosystems need to be explored as a means of integrating organizations, government and universities to integrate and digitize processes. Future works can also explore technological and sustainability paradoxes to identify the real potential of technologies in agriculture and the challenges related to the paradoxes, in order to understand whether human decisions about food production are in the right direction or are causing a collapse ecological and unrecoverable on the planet.

Author Contributions: Conceptualization, M.K.S.; methodology, M.K.S.; software, M.K.S. and L.B.F.; validation, M.K.S., L.B.F., L.S.N., C.R.F., K.F., P.A.Z. and N.L.B.; formal analysis, M.K.S., L.B.F., L.S.N., C.R.F., K.F., P.A.Z. and N.L.B., investigation, M.K.S., L.S.N. and C.R.F.; data curation, M.K.S., L.B.F., L.S.N., C.R.F., K.F., P.A.Z. and N.L.B.; writing-original draft preparation, M.K.S., L.S.N. and C.R.F.; writing-review and editing, M.K.S., L.B.F., L.S.N., C.R.F., K.F., P.A.Z. and N.L.B.; visualization, M.K.S., L.B.F., L.S.N., C.R.F., K.F., P.A.Z. and N.L.B.; supervision, M.K.S. and N.L.B.; project administration, M.K.S. and N.L.B; funding acquisition, N.L.B. All authors have read and agreed to the published version of the manuscript.

Funding: This study was financed in part by the Coordination for the Improvement of Higher Education Personnel (CAPES) - Finance Code 001, Brazil, in part by the National Council for Scientific and Technological Development (CNPq), and in part by the Research Support Foundation of Rio Grande do Sul (FAPERGS), Brazil.

Conflicts of Interest: The authors declare no conflict of interest.

\section{References}

1. Zhai, Z.; Martínez, J.F.; Beltran, V.; Martínez, N.L. Decision support systems for agriculture 4.0: Survey and challenges. Comput. Electron. Agric. 2020, 170, doi:10.1016/j.compag.2020.105256.

2. Harari, Y.N. A Brief History of Humankind: Sapiens; 2014;

3. Tekinerdogan, B. Strategies for Technological Innovation in Agriculture 4.0. Reports. Wageningen Univ. Wageningen, Netherlands 2018.

4. Grigg, D.B. Population Growth and Agrarian Change: An Historical Perspective. Geogr. J. 1980, 149, 237, 
doi:10.2307/633629.

5. Bidwell, P.W. The Agricultural Revolution in New England. Am. Hist. Rev. 1921, 26, 683, doi:10.2307/1836733.

6. Evans, J.R.; Lawson, T. From green to gold: Agricultural revolution for food security. J. Exp. Bot. 2020, 71, 2211-2215, doi:10.1093/jxb/eraa110.

7. Pingali, P.L. Green revolution: Impacts, limits, andthe path ahead. Proc. Natl. Acad. Sci. U. S. A. 2012, 109, 12302-12308, doi:10.1073/pnas.0912953109.

8. Khush, G. Green revolution: the way forward. Nature 2001.

9. Tey, Y.S.; Brindal, M. Factors influencing the adoption of precision agricultural technologies: A review for policy implications. Precis. Agric. 2012, 13, 713-730, doi:10.1007/s11119-012-9273-6.

10. Zhang, N.; Wang, M.; Agriculture, N.W.-C. and electronics in; 2002, U. Precision agriculture-a worldwide overview. Comput. Electron. Agric. 2002.

11. Sott, M.K.; Furstenau, L.B.; Kipper, L.M.; Giraldo, F.D.; Lopez-Robles, J.R.; Cobo, M.J.; Zahid, A.; Abbasi, Q.H.; Imran, M.A. Precision Techniques and Agriculture 4.0 Technologies to Promote Sustainability in the Coffee Sector: State of the Art, Challenges and Future Trends. IEEE Access 2020, 8, 149854-149867, doi:10.1109/ACCESS.2020.3016325.

12. Lasso, E.; Corrales, J.C. Towards an alert system for coffee diseases and pests in a smart farming approach based on semi-supervised learning and graph similarity. In Proceedings of the Advances in Intelligent Systems and Computing; Springer Verlag, 2018; Vol. 687, pp. 111-123.

13. Campbell, B.M.; Thornton, P.; Zougmoré, R.; van Asten, P.; Lipper, L. Sustainable intensification: What is its role in climate smart agriculture? Curr. Opin. Environ. Sustain. 2014, 8, 39-43, doi:10.1016/j.cosust.2014.07.002.

14. Adamides, G.; Kalatzis, N.; Stylianou, A.; Marianos, N.; Chatzipapadopoulos, F.; Giannakopoulou, M.; Papadavid, G.; Vassiliou, V.; Neocleous, D. Smart farming techniques for climate change adaptation in Cyprus. Atmosphere (Basel). 2020, 11, doi:10.3390/ATMOS11060557.

15. Lipper, L.; Thornton, P.; Campbell, B.M.; Baedeker, T.; Braimoh, A.; Bwalya, M.; Caron, P.; Cattaneo, A.; Garrity, D.; Henry, K.; et al. Climate-smart agriculture for food security. Nat. Clim. Chang. 2014, 4, 1068 1072, doi:10.1038/nclimate2437.

16. Staniškis, J.K. Sustainable consumption and production: How to make it possible. Clean Technol. Environ. Policy 2012, 14, 1015-1022, doi:10.1007/s10098-012-0535-9.

17. Bennett, B.E.; Carpenter, S.R.; Gordon, L.J.; Ramankutty, N.; Balvanera, P.; Campbell, B.; Cramer, W.; Foley, J.; Karlberg, L.; Liu, J.; et al. Toward a More Resilient Agriculture; 2014; Vol. 5;

18. Kim, J.; Kim, S.; Ju, C.; Son, H. Il Unmanned aerial vehicles in agriculture: A review of perspective of platform, control, and applications. IEEE Access 2019, 7, 105100-105115, doi:10.1109/ACCESS.2019.2932119.

19. Raparelli, E.; Bajocco, S. A bibliometric analysis on the use of unmanned aerial vehicles in agricultural and forestry studies. Int. J. Remote Sens. 2019, 40, 9070-9083, doi:10.1080/01431161.2019.1569793.

20. Terence, S.; Purushothaman, G. Systematic review of Internet of Things in smart farming. Trans. Emerg. Telecommun. Technol. 2020, 31, doi:10.1002/ett.3958.

21. Navarro, E.; Costa, N.; Pereira, A. A systematic review of iot solutions for smart farming. Sensors (Switzerland) 2020, 20, 1-29, doi:10.3390/s20154231.

22. Mekonnen, Y.; Namuduri, S.; Burton, L.; Sarwat, A.; Bhansali, S. Review - Machine Learning Techniques in Wireless Sensor Network Based Precision Agriculture. J. Electrochem. Soc. 2020, 167, 037522, 
doi:10.1149/2.0222003jes.

23. Liakos, K.G.; Busato, P.; Moshou, D.; Pearson, S.; Bochtis, D. Machine learning in agriculture: A review. Sensors (Switzerland) 2018, 18, doi:10.3390/s18082674.

24. Sharma, R.; Kamble, S.S.; Gunasekaran, A.; Kumar, V.; Kumar, A. A systematic literature review on machine learning applications for sustainable agriculture supply chain performance. Comput. Oper. Res. 2020, 119, doi:10.1016/j.cor.2020.104926.

25. Praveen, B.; Sharma, P. A review: The role of geospatial technology in precision agriculture. J. Public Aff. 2020, 20, doi:10.1002/pa.1968.

26. Kamilaris, A.; Kartakoullis, A.; Prenafeta-Boldú, F.X. A review on the practice of big data analysis in agriculture. Comput. Electron. Agric. 2017, 143, 23-37, doi:10.1016/j.compag.2017.09.037.

27. Wolfert, S.; Verdou, C.; Bogaardt, M. Big data in smart farming. Agric. Syst. 2017, 153, 69-80.

28. Bhakta, I.; Phadikar, S.; Majumder, K. State-of-the-art technologies in precision agriculture: a systematic review. J. Sci. Food Agric. 2019, 99, 4878-4888, doi:10.1002/jsfa.9693.

29. Pathak, H.S.; Brown, P.; Best, T. A systematic literature review of the factors affecting the precision agriculture adoption process. Precis. Agric. 2019, 20, 1292-1316, doi:10.1007/s11119-019-09653-x.

30. Cobo, M.J.; Lõpez-Herrera, A.G.; Herrera-Viedma, E.; Herrera, F. SciMAT: A new science mapping analysis software tool. J. Am. Soc. Inf. Sci. Technol. 2012, 63, 1609-1630, doi:10.1002/asi.22688.

31. Ofori, M.; El-Gayar, O. Drivers and challenges of precision agriculture: a social media perspective. Precis. Agric. 2020.

32. Hrustek, L. Sustainability driven by agriculture through digital transformation. Sustain. 2020, 12, 1-18, doi:10.3390/su12208596.

33. Khattab, A.; Abdelgawad, A.; Yelmarthi, K. Design and implementation of a cloud-based IoT scheme for precision agriculture; 2016; Vol. 0; ISBN 9781509057214.

34. Artuzo, F.D.; Foguesatto, C.R.; Silva, L.X. da Agricultura de precisão: inovação para a produção mundial de alimentos e otimização de insumos agrícolas; 2017; Vol. 13;.

35. Silva, C.B.; Do Vale, S.M.L.R.; Pinto, F.A.C.; Müller, C.A.S.; Moura, A.D. The economic feasibility of precision agriculture in Mato Grosso do Sul State, Brazil: A case study. Precis. Agric. 2007, 8, 255-265, doi:10.1007/s11119-007-9040-2.

36. Balafoutis, A.; Beck, B.; Fountas, S.; Vangeyte, J.; Van Der Wal, T.; Soto, I.; Gómez-Barbero, M.; Barnes, A.; Eory, V. Precision agriculture technologies positively contributing to ghg emissions mitigation, farm productivity and economics. Sustain. 2017, 9, doi:10.3390/su9081339.

37. Bongiovanni, R.; Lowenberg-Deboer, J. Precision agriculture and sustainability. Precis. Agric. 2004, 5, 359-387, doi:10.1023/B:PRAG.0000040806.39604.aa.

38. Gavioli, A.; de Souza, E.G.; Bazzi, C.L.; Schenatto, K.; Betzek, N.M. Identification of management zones in precision agriculture: An evaluation of alternative cluster analysis methods. Biosyst. Eng. 2019, 181, 86-102, doi:10.1016/j.biosystemseng.2019.02.019.

39. Paccioretti, P.; Córdoba, M.; Balzarini, M. FastMapping: Software to create field maps and identify management zones in precision agriculture. Comput. Electron. Agric. 2020, 175, doi:10.1016/j.compag.2020.105556.

40. Higgins, S.; Schellberg, J.; Bailey, J.S. Improving productivity and increasing the efficiency of soil nutrient management on grassland farms in the UK and Ireland using precision agriculture technology. Eur. J. Agron. 2019, 106, 67-74, doi:10.1016/j.eja.2019.04.001.

41. Mikula, K.; Izydorczyk, G.; Skrzypczak, D.; Mironiuk, M.; Moustakas, K.; Witek-Krowiak, A.; Chojnacka, 
K. Controlled release micronutrient fertilizers for precision agriculture - A review. Sci. Total Environ. 2020, 712, doi:10.1016/j.scitotenv.2019.136365.

42. Hedley, C. The role of precision agriculture for improved nutrient management on farms. J. Sci. Food Agric. 2015, 95, 12-19, doi:10.1002/jsfa.6734.

43. Gómez-Candón, D.; De Castro, A.I.; López-Granados, F. Assessing the accuracy of mosaics from unmanned aerial vehicle (UAV) imagery for precision agriculture purposes in wheat. Precis. Agric. 2014, 15, 44-56, doi:10.1007/s11119-013-9335-4.

44. Radoglou-Grammatikis, P.; Sarigiannidis, P.; Lagkas, T.; Moscholios, I. A compilation of UAV applications for precision agriculture. Comput. Networks 2020, 172, doi:10.1016/j.comnet.2020.107148.

45. Ofori, E.; Griffin, T.; Yeager, E. Duration analyses of precision agriculture technology adoption: what's influencing farmers' time-to-adoption decisions? Agric. Financ. Rev. 2020, 80, 647-664, doi:10.1108/AFR11-2019-0121.

46. Klerkx, L.; Jakku, E.; Labarthe, P. A review of social science on digital agriculture, smart farming and agriculture 4.0: New contributions and a future research agenda. NJAS - Wageningen J. Life Sci. 2019, 9091, doi:10.1016/j.njas.2019.100315.

47. Rose, D.C.; Chilvers, J. Agriculture 4.0: Broadening Responsible Innovation in an Era of Smart Farming. Front. Sustain. Food Syst. 2018, 2, doi:10.3389/fsufs.2018.00087.

48. Symeonaki, E.; Arvanitis, K.; Piromalis, D. A context-aware middleware cloud approach for integrating precision farming facilities into the IoT toward agriculture 4.0. Appl. Sci. 2020, 10, doi:10.3390/app10030813.

49. Huh, J.H.; Kim, K.Y. Time-based trend of carbon emissions in the composting process of swine manure in the context of agriculture 4.0. Processes 2018, 6, doi:10.3390/pr6090168.

50. Klerkx, L.; Rose, D. Dealing with the game-changing technologies of Agriculture 4.0: How do we manage diversity and responsibility in food system transition pathways? Glob. Food Sec. 2020, 24, doi:10.1016/j.gfs.2019.100347.

51. Pisanu, T.; Garau, S.; Ortu, P.; Schirru, L.; Macciò, C. Prototype of a low-cost electronic platform for real time greenhouse environment monitoring: An agriculture 4.0 perspective. Electron. 2020, 9, doi:10.3390/electronics9050726.

52. Furstenau, L.B.; Sott, M.K.; Kipper, L.M.; Machado, E.L.; Lopez-Robles, J.R.; Dohan, M.S.; Martin, M.J.C.; Zahid, A.; Abbasi, Q.H.; Imran, M.A. Link between sustainability and industry 4.0: trends, challenges and new perspectives. IEEE Access 2020, 1-1, doi:10.1109/access.2020.3012812.

53. Silva, A. de B.; Gomes, M.M.; da Costa, C.A.; da Rosa Righi, R.; Barbosa, J.L.V.; Pessin, G.; De Doncker, G.; Federizzi, G. Intelligent personal assistants: A systematic literature review. Expert Syst. Appl. 2020, 147, doi:10.1016/j.eswa.2020.113193.

54. Palmarini, R.; Erkoyuncu, J.A.; Roy, R.; Torabmostaedi, H. A systematic review of augmented reality applications in maintenance. Robot. Comput. Integr. Manuf. 2018, 49, 215-228, doi:10.1016/j.rcim.2017.06.002.

55. Bruzza, M.; Cabrera, A.; Tupia, M. Survey of the state of art based on PICOC about the use of artificial intelligence tools and expert systems to manage and generate tourist packages. 2017 Int. Conf. Infocom Technol. Unmanned Syst. Trends Futur. Dir. ICTUS 2017 2018, 2018-Janua, 290-296, doi:10.1109/ICTUS.2017.8286021.

56. Silva, F.S.T. da; da Costa, C.A.; Paredes Crovato, C.D.; da Rosa Righi, R. Looking at energy through the lens of Industry 4.0: A systematic literature review of concerns and challenges. Comput. Ind. Eng. 2020, 
143, doi:10.1016/j.cie.2020.106426.

57. Lezoche, M.; Panetto, H.; Kacprzyk, J.; Hernandez, J.E.; Alemany Díaz, M.M.E. Agri-food 4.0: A survey of the Supply Chains and Technologies for the Future Agriculture. Comput. Ind. 2020, 117, doi:10.1016/j.compind.2020.103187.

58. Saiz-Rubio, V.; Rovira-Más, F. From smart farming towards agriculture 5.0: A review on crop data management. Agronomy 2020, 10, doi:10.3390/agronomy10020207.

59. Furstenau, L.B.; Sott, M.K.; Homrich, A.J.O.; Kipper, L.M.; Al Abri, A.A.; Cardoso, T.F.; Lo' pez-Robles, J.R.; Cobo, M.J. 20 years of scientific evolution of cyber security: A science mapping; 2020; Vol. 0;

60. López-Robles, J.; Otegi-Olaso, J.; ... M.C.-... and E. in Editors: Jose Ramón Otegi, Nerea Toledo and Ianire Taboada Publisher: Asociación Española de Dirección e Ingeniería de Proyectos; 2020; ISBN 978-84-09-19740-8.

61. Severo, P.P.; Furstenau, L.B.; Sott, M.K.; Cossul, D.; Bender, M.S.; Bragazzi, N.L. Thirty years of human rights study in the web of science database (1990-2020). Int. J. Environ. Res. Public Health 2021, 18, 1-24, doi:10.3390/ijerph18042131.

62. Kolling, M.L.; Furstenau, L.B.; Sott, M.K.; Rabaioli, B.; Ulmi, P.H.; Bragazzi, N.L.; Tedesco, L.P.C. Data mining in healthcare: Applying strategic intelligence techniques to depict 25 years of research development. Int. J. Environ. Res. Public Health 2021, 18, 1-21, doi:10.3390/ijerph18063099.

63. Sott, M.K.; Furstenau, L.B.; Kipper, L.M.; Reckziegel Rodrigues, Y.P.; López-Robles, J.R.; Giraldo, F.D.; Cobo, M.J. Process modeling for smart factories: using science mapping to understand the strategic themes, main challenges and future trends. Bus. Process Manag. J. 2021, doi:10.1108/BPMJ-05-2020-0181.

64. Kipper, L.M.; Furstenau, L.B.; Hoppe, D.; Frozza, R.; Iepsen, S. Scopus scientific mapping production in industry 4.0 (2011-2018): a bibliometric analysis. Int. J. Prod. Res. 2020, 58, 1605-1627, doi:10.1080/00207543.2019.1671625.

65. Cobo, M.J.; Jürgens, B.; Herrero-Solana, V.; Martínez, M.A.; Herrera-Viedma, E. Industry 4.0: A perspective based on bibliometric analysis. Procedia Comput. Sci. 2018, 139, 364-371, doi:10.1016/j.procs.2018.10.278.

66. Furstenau, L.B.; Rabaioli, B.; Sott, M.K.; Cossul, D.; Bender, M.S.; Farina, E.M.J.D.M.; Filho, F.N.B.; Severo, P.P.; Dohan, M.S.; Bragazzi, N.L. A Bibliometric Network Analysis of Coronavirus during the First Eight Months of COVID-19 in 2020. Int. J. Environ. Res. Public Health 2021, 18, doi:10.3390/ijerph18030952.

67. Sott, M.K.; Bender, M.S.; Furstenau, L.B.; Machado, L.M.; Cobo, M.J.; Bragazzi, N.L. 100 Years of Scientific Evolution of Work and Organizational Psychology: A Bibliometric Network Analysis From 1919 to 2019. Front. Psychol. 2020, 11, doi:10.3389/fpsyg.2020.598676.

68. Furstenau, L.B.; Sott, M.K.; Homrich, A.J.O.; Kipper, L.M.; Dohan, M.S.; López-Robles, J.R.; Cobo, M.J.; Tortorella, G.L. An overview of 42 years of lean production: applying bibliometric analysis to investigate strategic themes and scientific evolution structure. Technol. Anal. Strateg. Manag. 2021, 1-20, doi:10.1080/09537325.2020.1865530.

69. Callon, M.; Courtial, J.P.; Laville, F. Co-word analysis as a tool for describing the network of interactions between basic and technological research: The case of polymer chemsitry. Scientometrics 1991, 22, 155205, doi:10.1007/BF02019280.

70. Coulter, N.; Monarch, I.; Konda, S. Software engineering as seen through its research literature: a study in co-word analysis. J. Am. Soc. Inf. Sci. 1998, 49, 1206-1223, doi:10.1002/(SICI)10974571(1998)49:13<1206::AID-ASI7>3.0.CO;2-F.

71. Chancellor, W.J.; Goronea, M.A. Effects of spatial variability of nitrogen, moisture, and weeds on the 
advantages of site-specific applications for wheat. Trans. Am. Soc. Agric. Eng. 1994, 37, 717-724, doi:10.13031/2013.28132.

72. Seeley, M.W. The future of serving agriculture with weather/climate information and forecasting: some indications and observations. Agric. For. Meteorol. 1994, 69, 47-59, doi:10.1016/0168-1923(94)90080-9.

73. Blackmore, S. Precision farming: an introduction. Outlook Agric. 1994, 23, 275-280, doi:10.1177/003072709402300407.

74. Cannon, M.E.; McKenzie, R.C.; Lachapelle, G. Soil salinity mapping with electromagnetic induction and satellite-based navigation methods. Can. J. Soil Sci. 1994, 74, 335-343, doi:10.4141/cjss94-046.

75. Wallace, A. High-precision agriculture is an excellent tool for conservation of natural resources. Commun. Soil Sci. Plant Anal. 1994, 25, 45-49, doi:10.1080/00103629409369002.

76. Librán-Embid, F.; Klaus, F.; Tscharntke, T.; Grass, I. Unmanned aerial vehicles for biodiversity-friendly agricultural landscapes - A systematic review. Sci. Total Environ. 2020, 732, doi:10.1016/j.scitotenv.2020.139204.

77. Dalamagkidis, K. Definitions and terminology. Handb. Unmanned Aer. Veh. 2015, 43-55, doi:10.1007/97890-481-9707-1_92.

78. Zha, H.; Miao, Y.; Wang, T.; Li, Y.; Zhang, J.; Sun, W.; Feng, Z.; Kusnierek, K. Improving unmanned aerial vehicle remote sensing-based rice nitrogen nutrition index prediction with machine learning. Remote Sens. 2020, 12, 215, doi:10.3390/rs12020215.

79. Otto, A.; Agatz, N.; Campbell, J.; Golden, B.; Pesch, E. Optimization approaches for civil applications of unmanned aerial vehicles (UAVs) or aerial drones: A survey. Networks 2018, 72, 411-458, doi:10.1002/net.21818.

80. Fu, Z.; Jiang, J.; Gao, Y.; Krienke, B.; Wang, M.; Zhong, K.; Cao, Q.; Tian, Y.; Zhu, Y.; Cao, W.; et al. Wheat growth monitoring and yield estimation based on multi-rotor unmanned aerial vehicle. Remote Sens. 2020, 12, doi:10.3390/rs12030508.

81. Puri, V.; Nayyar, A.; Raja, L. Agriculture drones: A modern breakthrough in precision agriculture. J. Stat. Manag. Syst. 2017, 20, 507-518, doi:10.1080/09720510.2017.1395171.

82. Lee, H.; Wang, J.; Leblon, B. Intra-Field Canopy Nitrogen Retrieval from Unmanned Aerial Vehicle Imagery for Wheat and Corn Fields. Can. J. Remote Sens. 2020, 46, 1-19, doi:10.1080/07038992.2020.1788384.

83. García-Martínez, H.; Flores-Magdaleno, H.; Ascencio-Hernández, R.; Khalil-Gardezi, A.; TijerinaChávez, L.; Mancilla-Villa, O.R.; Vázquez-Peña, M.A. Corn grain yield estimation from vegetation indices, canopy cover, plant density, and a neural network using multispectral and rgb images acquired with unmanned aerial vehicles. Agric. 2020, 10, 1-24, doi:10.3390/agriculture10070277.

84. Zhang, S.; Zhao, G. A harmonious satellite-unmanned aerial vehicle-ground measurement inversion method for monitoring salinity in coastal saline soil. Remote Sens. 2019, 11, doi:10.3390/rs11141700.

85. Chandra, A.; McNamara, K.E.; Dargusch, P. Climate-smart agriculture: perspectives and framings. Clim. Policy 2018, 18, 526-541, doi:10.1080/14693062.2017.1316968.

86. Taylor, M. Climate-smart agriculture: what is it good for? J. Peasant Stud. 2018, 45, 89-107, doi:10.1080/03066150.2017.1312355.

87. Aryal, J.P.; Farnworth, C.R.; Khurana, R.; Ray, S.; Sapkota, T.B.; Rahut, D.B. Does women's participation in agricultural technology adoption decisions affect the adoption of climate-smart agriculture? Insights from Indo-Gangetic Plains of India. Rev. Dev. Econ. 2020, 24, 973-990, doi:10.1111/rode.12670.

88. Everest, B. Farmers' adaptation to climate-smart agriculture (CSA) in NW Turkey. Environ. Dev. Sustain. 
2020, doi:10.1007/s10668-020-00767-1.

89. Ardakani, Z.; Bartolini, F.; Brunori, G. Economic modeling of climate-smart agriculture in Iran. New Medit 2019, 2019, 29-40, doi:10.30682/nm1901c.

90. Makate, C.; Makate, M.; Mango, N.; Siziba, S. Increasing resilience of smallholder farmers to climate change through multiple adoption of proven climate-smart agriculture innovations. Lessons from Southern Africa. J. Environ. Manage. 2019, 231, 858-868, doi:10.1016/j.jenvman.2018.10.069.

91. Hasan, M.K.; Desiere, S.; D’Haese, M.; Kumar, L. Impact of climate-smart agriculture adoption on the food security of coastal farmers in Bangladesh. Food Secur. 2018, 10, 1073-1088, doi:10.1007/s12571-0180824-1.

92. Dorsemaine, B.; Gaulier, J.P.; Wary, J.P.; Kheir, N.; Urien, P. Internet of Things: A Definition and Taxonomy. Proc. - NGMAST 2015 9th Int. Conf. Next Gener. Mob. Appl. Serv. Technol. 2016, 72-77, doi:10.1109/NGMAST.2015.71.

93. Hwang, S. A network clock model for time awareness in the Internet of things and artificial intelligence applications. J. Supercomput. 2019, 75, 4309-4328, doi:10.1007/s11227-019-02774-0.

94. Kour, V.P.; Arora, S. Recent Developments of the Internet of Things in Agriculture: A Survey. IEEE Access 2020, 8, 129924-129957, doi:10.1109/ACCESS.2020.3009298.

95. Sadowski, S.; Spachos, P. Wireless technologies for smart agricultural monitoring using internet of things devices with energy harvesting capabilities; 2020; Vol. 172;.

96. Jayaraman, P.P.; Yavari, A.; Georgakopoulos, D.; Morshed, A.; Zaslavsky, A. Internet of things platform for smart farming: Experiences and lessons learnt. Sensors (Switzerland) 2016, 16, doi:10.3390/s16111884.

97. Jin, X.B.; Yu, X.H.; Wang, X.Y.; Bai, Y.T.; Su, T.L.; Kong, J.L. Deep learning predictor for sustainable precision agriculture based on internet of things system. Sustain. 2020, 12, doi:10.3390/su12041433.

98. Hussain Awan, S. Role of Internet of Things (IoT) with Blockchain Technology for the Development of Smart Farming. J. Mech. Contin. Math. Sci. 2019, 14, doi:10.26782/jmcms.2019.10.00014.

99. Gsangaya, K.R.; Hajjaj, S.S.H.; Sultan, M.T.H.; Hua, L.S. Portable, wireless, and effective internet of things-based sensors for precision agriculture. Int. J. Environ. Sci. Technol. 2020, 17, 3901-3916, doi:10.1007/s13762-020-02737-6.

100. Lombardi, F.; Lualdi, M. Step-frequency ground penetrating radar for agricultural soil morphology characterisation. Remote Sens. 2019, 11, doi:10.3390/rs11091075.

101. Corassa, G.M.; Santi, A.L.; da Silva, V.R.; Baron, F.A.; Reimche, G.B.; Fioresi, D.; Della Flora, D.P. Soil chemical attributes restricting grain yield in Oxisols under no-tillage system. Pesqui. Agropecu. Bras. 2018, 53, 1203-1212, doi:10.1590/S0100-204X20180011000002.

102. Barbosa, D.P.; Bottega, E.L.; Valente, D.S.M.; Santos, N.T.; Guimarães, W.D. Delineation of homogeneous zones based on geostatistical models robust to outliers. Rev. Caatinga 2019, 32, 472-481, doi:10.1590/198321252019v32n220rc.

103. Carvalho, L.C.C.; da Silva, F.M.; Ferraz, G.A.E.S.; Stracieri, J.; Ferraz, P.F.P.; Ambrosano, L. Geostatistical analysis of arabic coffee yield in two crop seasons. Rev. Bras. Eng. Agric. e Ambient. 2017, 21, 410-414, doi:10.1590/1807-1929/agriambi.v21n6p410-414.

104. Gao, J. Integration of GPS with remote sensing and GIS: Reality and prospect; 2002; Vol. 68;.

105. Hofmann-Wellenhof, B.; Lichtenegger, H.; Collins, J. Global positioning system: theory and practice. 2012.

106. Si, J.; Niu, Y.; Lu, J.; Zhang, H. High-Precision Estimation of Steering Angle of Agricultural Tractors Using GPS and Low-Accuracy MEMS. IEEE Trans. Veh. Technol. 2019, 68, 11738-11745, 
doi:10.1109/TVT.2019.2949298.

107. Palaniswami, C.; Gopalasundaram, P.; Bhaskaran, A. Application of GPS and GIS in Sugarcane Agriculture. Sugar Tech 2011, 13, 360-365, doi:10.1007/s12355-011-0098-9.

108. Khosro Anjom, F.; Vougioukas, S.G.; Slaughter, D.C. Development and application of a strawberry yield-monitoring picking cart. Comput. Electron. Agric. 2018, 155, 400-411, doi:10.1016/j.compag.2018.10.038.

109. Virk, S.S.; Fulton, J.P.; Porter, W.M.; Pate, G.L. Row-crop planter performance to support variable-rate seeding of maize. Precis. Agric. 2020, 21, 603-619, doi:10.1007/s11119-019-09685-3.

110. Thrikawala, S.; Weersink, A.; Fox, G.; Kachanoski, G. Economic Feasibility of Variable-Rate Technology for Nitrogen on Corn. Am. J. Agric. Econ. 1999, 81, 914-927, doi:10.2307/1244334.

111. Zhao, C.; Lee, W.S.; He, D. Immature green citrus detection based on colour feature and sum of absolute transformed difference (SATD) using colour images in the citrus grove. Comput. Electron. Agric. 2016, 124, 243-253, doi:10.1016/j.compag.2016.04.009.

112. Sabzi, S.; Abbaspour-Gilandeh, Y. Using video processing to classify potato plant and three types of weed using hybrid of artificial neural network and partincle swarm algorithm. Meas. J. Int. Meas. Confed. 2018, 126, 22-36, doi:10.1016/j.measurement.2018.05.037.

113. Wang, A.; Zhang, W.; Wei, X. A review on weed detection using ground-based machine vision and image processing techniques. Comput. Electron. Agric. 2019, 158, 226-240, doi:10.1016/j.compag.2019.02.005.

114. Rehman, T.U.; Mahmud, M.S.; Chang, Y.K.; Jin, J.; Shin, J. Current and future applications of statistical machine learning algorithms for agricultural machine vision systems. Comput. Electron. Agric. 2019, 156, 585-605, doi:10.1016/j.compag.2018.12.006.

115. Niedbała, G.; Kurasiak-Popowska, D.; Stuper-Szablewska, K.; Nawracała, J. Application of artificial neural networks to analyze the concentration of ferulic acid, deoxynivalenol, and nivalenol in winter wheat grain. Agric. 2020, 10, doi:10.3390/agriculture10040127.

116. Mendes, J.; Pinho, T.M.; Dos Santos, F.N.; Sousa, J.J.; Peres, E.; Boaventura-Cunha, J.; Cunha, M.; Morais, R. Smartphone applications targeting precision agriculture practices - A systematic review. Agronomy 2020, 10, doi:10.3390/agronomy10060855.

117. Bånkestad, D.; Wik, T. Growth tracking of basil by proximal remote sensing of chlorophyll fluorescence in growth chamber and greenhouse environments. Comput. Electron. Agric. 2016, 128, 77-86, doi:10.1016/j.compag.2016.08.004.

118. Young, E.O. Soil nutrient management: fueling agroecosystem sustainability. Int. J. Agric. Sustain. 2020, doi:10.1080/14735903.2020.1792679.

119. Vos, J. Nitrogen responses and nitrogen management in potato. Potato Res. 2009, 52, 305-317, doi:10.1007/s11540-009-9145-2.

120. Moshia, M.E.; Khosla, R.; Davis, J.G.; Westfall, D.G.; Doesken, K. Precision Manure Management on SiteSpecific Management Zones: Topsoil Quality and Environmental Impact. Commun. Soil Sci. Plant Anal. 2015, 46, 235-258, doi:10.1080/00103624.2014.967862.

121. Marchiol, L. Nanofertilisers. An outlook of crop nutrition in the fourth agricultural revolution. Ital. J. Agron. 2019, 14, 183-190, doi:10.4081/ija.2019.1367.

122. Storer, C.S.; Coldrick, Z.; Tate, D.J.; Donoghue, J.M.; Grieve, B. Towards phosphate detection in hydroponics using molecularly imprinted polymer sensors. Sensors (Switzerland) 2018, 18, doi:10.3390/s18020531. 
123. Hochman, Z.; Carberry, P.S.; Robertson, M.J.; Gaydon, D.S.; Bell, L.W.; McIntosh, P.C. Prospects for ecological intensification of Australian agriculture. Eur. J. Agron. 2013, 44, 109-123, doi:10.1016/j.eja.2011.11.003.

124. Mahlein, A.K.; Kuska, M.T.; Behmann, J.; Polder, G.; Walter, A. Hyperspectral sensors and imaging technologies in phytopathology: State of the art. Annu. Rev. Phytopathol. 2018, 56, 535-558.

125. Lu, B.; Dao, P.D.; Liu, J.; He, Y.; Shang, J. Recent advances of hyperspectral imaging technology and applications in agriculture. Remote Sens. 2020, 12, doi:10.3390/RS12162659.

126. Gonzalez-Dugo, V.; Hernandez, P.; Solis, I.; Zarco-Tejada, P.J. Using high-resolution hyperspectral and thermal airborne imagery to assess physiological condition in the context of wheat phenotyping. Remote Sens. 2015, 7, 13586-13605, doi:10.3390/rs71013586.

127. Diaz, M.; Guerra, R.; Horstrand, P.; Martel, E.; Lopez, S.; Lopez, J.F.; Sarmiento, R. Real-Time Hyperspectral Image Compression onto Embedded GPUS. IEEE J. Sel. Top. Appl. Earth Obs. Remote Sens. 2019, 12, 2792-2809, doi:10.1109/JSTARS.2019.2917088.

128. Zovko, M.; Žibrat, U.; Knapič, M.; Kovačić, M.B.; Romić, D. Hyperspectral remote sensing of grapevine drought stress. Precis. Agric. 2019, 20, 335-347, doi:10.1007/s11119-019-09640-2.

129. Nagasubramanian, K.; Jones, S.; Sarkar, S.; Singh, A.K.; Singh, A.; Ganapathysubramanian, B. Hyperspectral band selection using genetic algorithm and support vector machines for early identification of charcoal rot disease in soybean stems. Plant Methods 2018, 14, doi:10.1186/s13007-0180349-9.

130. Matzrafi, M.; Herrmann, I.; Nansen, C.; Kliper, T.; Zait, Y.; Ignat, T.; Siso, D.; Rubin, B.; Karnieli, A.; Eizenberg, H. Hyperspectral technologies for assessing seed germination and Trifloxysulfuron-Methyl response in amaranthus palmeri (Palmer amaranth). Front. Plant Sci. 2017, 8, doi:10.3389/fpls.2017.00474.

131. Gené-Mola, J.; Gregorio, E.; Auat Cheein, F.; Guevara, J.; Llorens, J.; Sanz-Cortiella, R.; Escolà, A.; RosellPolo, J.R. Fruit detection, yield prediction and canopy geometric characterization using LiDAR with forced air flow. Comput. Electron. Agric. 2020, 168, doi:10.1016/j.compag.2019.105121.

132. Maimaitijiang, M.; Sagan, V.; Sidike, P.; Hartling, S.; Esposito, F.; Fritschi, F.B. Soybean yield prediction from UAV using multimodal data fusion and deep learning. Remote Sens. Environ. 2020, 237, doi:10.1016/j.rse.2019.111599.

133. Ballester, C.; Hornbuckle, J.; Brinkhoff, J.; Smith, J.; Quayle, W. Assessment of in-season cotton nitrogen status and lint yield prediction from unmanned aerial system imagery. Remote Sens. 2017, 9, doi:10.3390/rs9111149.

134. Zecha, C.W.; Peteinatos, G.G.; Link, J.; Claupein, W. Utilisation of ground and airborne optical sensors for nitrogen level identification and yield prediction in wheat. Agric. 2018, 8, doi:10.3390/agriculture8060079.

135. Niedbała, G. Application of artificial neural networks for multi-criteria yield prediction ofwinter rapeseed. Sustain. 2019, 11, doi:10.3390/su11020533.

136. Pantazi, X.E.; Moshou, D.; Alexandridis, T.; Whetton, R.L.; Mouazen, A.M. Wheat yield prediction using machine learning and advanced sensing techniques. Elsevier 2016, doi:10.1016/j.compag.2015.11.018.

137. Abbas, F.; Afzaal, H.; Farooque, A.A.; Tang, S. Crop yield prediction through proximal sensing and machine learning algorithms. Agronomy 2020, 10, doi:10.3390/AGRONOMY10071046.

138. Gómez, D.; Salvador, P.; Sanz, J.; Casanova, J.L. Potato yield prediction using machine learning techniques and Sentinel 2 data. Remote Sens. 2019, 11, doi:10.3390/rs11151745.

139. Feng, L.; Zhang, Z.; Ma, Y.; Du, Q.; Williams, P.; Drewry, J.; Luck, B. Alfalfa yield prediction using UAV- 
based hyperspectral imagery and ensemble learning. Remote Sens. 2020, 12, doi:10.3390/rs12122028.

140. Haboudane, D.; Miller, J.R.; Tremblay, N.; Zarco-Tejada, P.J.; Dextraze, L. Integrated narrow-band vegetation indices for prediction of crop chlorophyll content for application to precision agriculture; 2002; Vol. 81;

141. Haboudane, D.; Miller, J.R.; Pattey, E.; Zarco-Tejada, P.J.; Strachan, I.B. Hyperspectral vegetation indices and novel algorithms for predicting green LAI of crop canopies: Modeling and validation in the context of precision agriculture. Remote Sens. Environ. 2004, 90, 337-352, doi:10.1016/j.rse.2003.12.013.

142. Hetzroni, A.; Edan, Y.; Alchanatis, V. Imaging techniques for chemical application on crops; 1997; Vol. 25;.

143. Yanai, J.; Lee, C.K.; Kaho, T.; Iida, M.; Matsui, T.; Umeda, M.; Kosaki, T. Geostatistical analysis of soil chemical properties and rice yield in a paddy field and application to the analysis of yield-determining factors. Soil Sci. Plant Nutr. 2001, 47, 291-301, doi:10.1080/00380768.2001.10408393.

144. Di, H.J.; Cameron, K.C. Nitrate leaching in temperate agroecosystems: Sources, factors and mitigating strategies. Nutr. Cycl. Agroecosystems 2002, 64, 237-256, doi:10.1023/A:1021471531188.

145. Nowak, P. Agriculture and change: The promises and pitfalls of precision. Commun. Soil Sci. Plant Anal. 1998, 29, 1537-1541, doi:10.1080/00103629809370047.

146. Weiss, M.D. Precision Farming and Spatial Economic Analysis: Research Challenges and Opportunities. Am. J. Agric. Econ. 1996, 78, 1275-1280, doi:10.2307/1243506.

147. Vanden Heuvel, R.M. The promise of precision agriculture. J. Soil Water Conserv. 1996, 51, 38.

148. Lowenberg-DeBoer, J. Precision Farming and the New Information Technology: Implications for Farm Management, Policy, and Research: Discussion. Am. J. Agric. Econ. 1996, 78, 1281-1284, doi:10.2307/1243507.

149. Cook, S.E.; Bramley, R.G.V. Precision agriculture - Opportunities, benefits and pitfalls of site-specific crop management in Australia. Aust. J. Exp. Agric. 1998, 38, 753-763, doi:10.1071/EA97156.

150. Schepers, J.S.; Francis, D.D. Precision agriculture - What's in our future. Commun. Soil Sci. Plant Anal. 1998, 29, 1463-1469, doi:10.1080/00103629809370043.

151. Zhang, C.; Kovacs, J.M. The application of small unmanned aerial systems for precision agriculture: A review. Precis. Agric. 2012, 13, 693-712, doi:10.1007/s11119-012-9274-5.

152. Möckel, S. "Best available techniques" as a mandatory basic standard for more sustainable agricultural land use in Europe? Land use policy 2015, 47, 342-351, doi:10.1016/j.landusepol.2015.04.021.

153. Gago, J.; Douthe, C.; Coopman, R.E.; Gallego, P.P.; Ribas-Carbo, M.; Flexas, J.; Escalona, J.; Medrano, H. UAVs challenge to assess water stress for sustainable agriculture. Agric. Water Manag. 2015, 153, 9-19, doi:10.1016/j.agwat.2015.01.020.

154. Leite, A.E.; De Castro, R.; Jabbour, C.J.C.; Batalha, M.O.; Govindan, K. Agricultural production and sustainable development in a Brazilian region (Southwest, São Paulo State): Motivations and barriers to adopting sustainable and ecologically friendly practices. Int. J. Sustain. Dev. World Ecol. 2014, 21, 422429, doi:10.1080/13504509.2014.956677.

155. Moura, S.S.; França, L.T.; Pereira, V.S.; Teodoro, P.E.; Baio, F.H.R. Seeding rate in soybean according to the soil apparent electrical conductivity. An. Acad. Bras. Cienc. 2020, 92, 1-13, doi:10.1590/00013765202020181112.

156. Domínguez-Niño, J.M.; Oliver-Manera, J.; Girona, J.; Casadesús, J. Differential irrigation scheduling by an automated algorithm of water balance tuned by capacitance-type soil moisture sensors. Agric. Water Manag. 2020, 228, doi:10.1016/j.agwat.2019.105880.

157. Perron, I.; Cambouris, A.N.; Chokmani, K.; Gutierrez, M.F.V.; Zebarth, B.J.; Moreau, G.; Biswas, A.; 
Adamchuk, V. Delineating soil management zones using a proximal soil sensing system in two commercial potato fields in new brunswick, canada. Can. J. Soil Sci. 2018, 98, 724-737, doi:10.1139/cjss2018-0063.

158. Zhao, Q.; Huang, J. Roadmap of Resource Saving Agricultural Science and Technology Development. In Agricultural Science E Technology in China: A Roadmap to 2050; Springer Berlin Heidelberg, 2011; pp. 80-99.

159. Bolfe, É.L.; Jorge, L.A. de C.; Sanches, I.D.; Júnior, A.L.; Costa, C.C. da; Victoria, D. de C.; Inamasu, R.Y.; Grego, C.R.; Ferreira, V.R.; Ramirez, A.R. Precision and digital agriculture: Adoption of technologies and perception of Brazilian farmers. Agric. 2020, 10, 1-16, doi:10.3390/agriculture10120653.

160. Contreras-Medina, D.I.; Sánchez Osorio, E.; Olvera Vargas, L.A.; Romero Romero, Y. Technology roadmapping architecture based on knowledge management: Case study for improved indigenous coffee production from Guerrero, Mexico. J. Sensors 2019, 2019, doi:10.1155/2019/5860905.

161. Jones, C.; Pimdee, P. Innovative ideas: Thailand 4.0 and the fourth industrial revolution. Asian Int. J. Soc. Sci. 2017, 17, 4-35, doi:10.29139/aijss.20170101.

162. Puncreobutr, V. The policy drive of Thailand 4.0; 2017; Vol. 3;

163. Ferrag, M.A.; Shu, L.; Yang, X.; Derhab, A.; Maglaras, L. Security and Privacy for Green IoT-Based Agriculture: Review, Blockchain Solutions, and Challenges. IEEE Access 2020, 8, 32031-32053, doi:10.1109/ACCESS.2020.2973178.

164. Hussein, A.R.H. Internet of Things (IOT): Research challenges and future applications; 2019; Vol. 10;.

165. Zhang, X.; Cao, Z.; Dong, W. Overview of Edge Computing in the Agricultural Internet of Things: Key Technologies, Applications, Challenges. IEEE Access 2020, 8, 141748-141761, doi:10.1109/ACCESS.2020.3013005.

166. Fountas, S.; Espejo-Garcia, B.; Kasimati, A.; Mylonas, N.; Darra, N. The Future of Digital Agriculture: Technologies and Opportunities. IT Prof. 2020, 22, 24-28, doi:10.1109/MITP.2019.2963412.

167. Lélé, S.; 1991, U. Sustainable development: a critical review. Elsevier 1991.

168. Engebretsen, E.; Heggen, K.; Das, S.; Farmer, P.; Ottersen, O.P. Paradoxes of sustainability with consequences for health. Lancet Glob. Heal. 2016, 4, e225-e226, doi:10.1016/S2214-109X(16)00038-3.

169. Patriarca, F.; Chiarolla, M.; DEcclesia, R.; Franzini, M.; Rodano, G.; Sardoni, C.; Ventura, L.; Zelli, R. Time-to-build, Obsolescence and the Technological Paradox The School's main goals The Editorial Board of the Working Papers TIME-TO-BUILD, OBSOLESCENCE AND THE TECHNOLOGICAL PARADOX; 2012;

170. Vasa, L.; Angeloska, A.; Trendov, N.M. Comparative analysis of circular agriculture development in selected Western Balkan countries based on sustainable performance indicators. Econ. Ann. 2017, 168, 44-47, doi:10.21003/ea.V168-09.

171. Yılmaz, A.; Arıcıoğlu, M.A.; Gülnar, N. 4.0 For Agriculture. Eur. J. Bus. Manag. Res. 2020, 5, doi:10.24018/ejbmr.2020.5.3.364.

172. Odara, S.; Khan, Z.; Ustun, T.S. Integration of Precision Agriculture and SmartGrid technologies for sustainable development. Proc. - 2015 IEEE Int. Conf. Technol. Innov. ICT Agric. Rural Dev. TIAR 2015 2015, 84-89, doi:10.1109/TIAR.2015.7358536.

173. Nascimento, L. da S.; Reichert, F.M.; Janissek-Muniz, R.; Zawislak, P.A. Dynamic interactions among knowledge management, strategic foresight and emerging technologies. J. Knowl. Manag. 2020, doi:10.1108/JKM-01-2020-0044.

174. Zawislak, P.A.; Alves, A.C.; Tello-Gamarra, J.; Barbieux, D.; Reichert, F.M. Innovation capability: From technology development to transaction capability. J. Technol. Manag. Innov. 2012, 7, 14-25, 
doi:10.4067/s0718-27242012000200002.

175. Oliveira, C.A.O.; Ruffoni, E.P.; Maçada, A.C.G.; Padula, Â.D. Innovation capabilities in the food processing industry in Brazil. Br. Food J. 2019, 121, 2901-2918, doi:10.1108/BFJ-10-2018-0647.

176. Valdez-De-Leon, O. How to Develop a Digital Ecosystem - a Practical Framework. Technol. Innov. Manag. Rev. 2019, 9, 43-54, doi:10.22215/timreview/1260.

177. Santini, M.A.F.; Faccin, K.; Balestrin, A.; Volkmer Martins, B. How the relational structure of universities influences research and development results. J. Bus. Res. 2021, 125, 155-163, doi:10.1016/j.jbusres.2020.12.018.

178. Thomas, E.; Faccin, K.; Asheim, B.T. Universities as orchestrators of the development of regional innovation ecosystems in emerging economies. Growth Change 2020, doi:10.1111/grow.12442. 